\title{
Scientific effects of Triple Helix interactions among research institutes, industries and universities
}

\author{
Yi Zhang, Kaihua Chen and Xiaolan Fu
}

\begin{abstract}
The Triple Helix (TH) interactions among innovation organizations have become increasingly important for national science and technology development. Yet, few studies in the extant literature have investigated their effects on the participants' scientific performance. This study fills this research gap by exploring whether the scientific performance of research institutes is influenced by their $\mathrm{TH}$ interactions with industries or/and universities. More specifically, the dynamic patterns of bilateral and trilateral interactions of the Chinese Academy of Sciences (CAS) as a typical example with industries or/and universities, as well as their effects on the CAS's scientific performance are revealed by means of the TH theoretical framework. The research result shows that their bilateral and trilateral interactions not only directly and significantly improved the CAS's scientific performance but also moderately enhanced the effects of research investments on that performance. It is confirmed as expected that the bilateral interactions between research institutes and universities exhibit a more positive and significant effect on scientific performance in both direct and indirect ways compared with the bilateral interactions between research institutes and industries. In summary, this study extends the analytical scope of $\mathrm{TH}$ empirical studies by implementing an exploring research on the TH effects from the perspective of academic institutes.
\end{abstract}

Keywords: Triple helix interactions; Industry-University-Research Institute Relations; Scientific performance; Chinese Academy of Sciences 


\section{Introduction}

This article attempts to extend Triple Helix (TH) studies by uncovering whether the TH interactions are beneficial to the scientific performance of academic institutes within the national S\&T innovation system. This endeavor is implemented based on the previous studies which have made substantial contributions to developing a benchmarking TH framework for understanding the dynamic TH interactions among three institutional actors: University-Industry-Government (UIG) (e.g., Champenois and Etzkowitz, 2017; Gustafsson and Jarvenpaa, 2018; Leydesdorff, 2018; Mêgnigbêto, 2018a, 2018b; Park and Leydesdorff, 2010). More recently, some exploratory studies have been devoted to investigating how the TH interactions influence the innovation performance of involved economic institutes (Guerrero and Urbano, 2017; Ryan et al., 2018). Yet, the impact of TH interactions on the scientific performance of academic institutions remains under-researched. The objective of this paper hence aims to fill in this important gap in the TH study by examining the scientific effects of TH interactions from the perspective of academic institutions.

It is well accepted that the model of innovation has changed from the previous linear model to the TH one in today's knowledge-based economy (Choi et al., 2015). Since the TH innovation model is conducive to enhancing the national innovation capacities and achieving endogenous economic development, more and more countries, including both developed and developing ones, introduced a series of incentives to foster linkages among various players in the TH framework. In this context, a considerable volume of studies have been devoted to explorations of dynamic interaction between/among innovation organizations (e.g., Kwon et al., 2012; Leydesdorff and Sun, 2009; Park and Leydesdorff, 2010; Ranga and Etzkowitz, 2013; Santoro et al., 2018; Villarreal and Calvo, 2015), and an important innovation theory, namely, TH theory developed by Etzkowitz and Leydesdorff (1995), appeared. This theory presents a general paradigm and analytical framework and method for investigating the $\mathrm{TH}$ relations among institutional actors at the system level (Ivanova and Leydesdorff, 2014; Strand et al., 2017), and emphasizes that the TH interactions among UIG are the important antecedent of knowledge production and technological innovation (Etzkowitz, 2003; Etzkowitz and Leydesdorff, 2000).

The flexibility and generality of the TH analytical method inspired the scholars to use it to investigate the pattern of dynamic interaction among institutional sectors such as universities, industries, and governments (Choi et al., 2015; Gustafsson and Jarvenpaa, 2018; Hong and Su, 2013; Leydesdorff, 2003, 2018; Mêgnigbêto, 2018b; Park and Leydesdorff, 2010). Their investigations have contributed to explaining how the $\mathrm{TH}$ interactions take place and whether they generate a synergic effect, but these studies are mainly limited to descriptions of characteristics of TH relations. 
To date, the research on how the TH interactions influence the participants' performance is still scant (Li et al., 2016). Acknowledging this research gap, the present study attempts to examine whether the TH relationships of (public) research institutes with industries and universities benefit their scientific performance. This study is situated in an interesting research setting of China's science and technology (S\&T) innovation system where the research institutes, especially the public ones, act as a critical knowledge creator and have long been serving as an important innovation source for the industrial sector (Chen et al., 2017).

Within China's science, technology and innovation (STI) system, the government plays an important role in promoting innovation development. Specifically, on the one hand, the government acts as a participator by setting up and funding the research institutes; on the other hand, the government acts as a supervision institute by issuing a series of S\&T policies. In this statistic model of an innovation system, the R\&D resources are mainly concentrated in the government-sponsored institutes, for example, the research institutes such as the Chinese Academy of Sciences (CAS), rather than the enterprises. As a result, many domestic enterprises have poor innovative capabilities (Zhang et al., 2016). In order to enhance the innovation performance of the industrial enterprises, the Chinese government has issued various S\&T policies to promote the bilateral and trilateral interactions among "Industry-University-Research Institute" (IUR), which are expected to promote the production, transfer and application of S\&T knowledge (Lavie and Drori, 2012; Schillebeeckx et al., 2015). So far, enhancing IUR synergy has been deemed to be a key strategy and approach for improving China's innovative capability in several important released government documents (Gao et al., 2014; Liang et al., 2012; Zhang et al., 2016). However, few studies have investigated the current state and effectiveness of IUR interactions in China. Therefore, a rigorous evaluation of IUR synergy and its impacts in China will not only serve to fill in a significant gap in the literature. It will also have important policy implications for effective management of the national S\&T innovation system (Jin and Luo, 2009).

In this study, the TH analytical method is employed to investigate the IUR relationships in China and uncover their impacts on the scientific performance of the participating research institutions. This study therefore contributes to extant literature in the following aspects. Firstly, this study reveals how the research institutes' bilateral and trilateral interactions with industries or/and universities influence their scientific performance. As far as we know, there are still few attempts to examine the scientific impacts of $\mathrm{TH}$ interactions between/among the three institutional actors of IUR on the participating research institute. Thus this paper contributes to extant literature by extending the analytical scope of TH empirical studies. Secondly, in contrast to abundant studies that have investigated how knowledge transfers from academic institutes to industry sectors and the 
effects on the firms' innovation performance (Fu and Li, 2017; Elvekrok et al., 2018; Jones and de Zubielqui, 2017; Perkmann et al., 2011), few efforts have been made to clarify how the research interactions with industry sectors affect the academic institutes' scientific performance. This study may be one of few studies devoted to filling this research gap.

The rest of this article is organized as follows. The theoretical base and hypotheses are presented in Section 2. The data source and measure method are elaborated in Section 3. The research results are illustrated in Section 4. The implications for theory, policy and practice are discussed in Section 5. Finally, the conclusions and limitations are summarized in Section 6.

\section{Theoretical base and Hypotheses}

\subsection{Theoretical base}

Since the mode of knowledge production has changed from Mode 1 (i.e., knowledge production in the single disciplinary context) to Mode 2 (i.e., knowledge production in the cross-disciplinary or inter-organizational context), the communication and coordination across institutional boundaries have been deemed critical for the realization of improving national innovative capabilities (Yoon and Park, 2017). In this context, Etzkowitz and Leydesdorff (1995) developed the TH theory, which is about the exchange and evolutionary mechanisms among three institutional actors: universities, industries and governments ( $\mathrm{Li}$ et al., 2016). This theory highlights UIG interactive relations, namely the TH model, as the core of knowledge production and technology innovation (Etzkowitz, 2003; Etzkowitz and Leydesdorff, 2000). In the TH model, three institutional actors of the UIG system are no longer separate institutional spheres but need to intermingle with one another to achieve self-sustaining development (self-organization) (Choi et al., 2015). Since TH interactions can expand innovative resources, facilitate interactive learning between institutional actors (Lee and Kim, 2016), and create an effective mechanism for the development of innovations (Ivanova and Leydesdorff, 2014b), the pattern of TH relations has been deemed as the most desirable model of generating innovation (Yoon and Park, 2017) and achieving endogenous economic development (Choi et al., 2015). This suggests that the $\mathrm{TH}$ relations create an effective institutional arrangement for knowledge-based innovation systems, among which there is no sharp boundary between the knowledge producers and users (Champenois and Etzkowitz, 2017), but there is rather a sharing of new ideas, information, knowledge, personnel and other resources among innovation organizations (Etzkowitz and Dzisah, 2008).

It should be noted that the TH theory has evolved from an initial TH model (Etzkowitz and Leydesdorff, 1995, 2000) to Quadruple Helix by adding as the fourth helix "civil society" (Afonso et 
al., 2012; McAdam and Debackere, 2018; Miller et al., 2018), Quintuple Helix embedding Quadruple Helix and extending to the social and environment ecology (Carayannis and Campbell, 2010; Carayannis et al., 2018), ...., and the N-Tuple Helix (Leydesdorff, 2012; Park, 2014a,2014b). The appearance of the N-Tuple Helix indicates that there are more helices apart from the initial $\mathrm{TH}$ in the innovation system (Carayannis and Campbell, 2009, 2010; Kwon et al., 2012; Leydesdorff, 2010; Leydesdorff and Sun, 2009), which would attract the scholars' increasing attention to the roles that institutional organizations assume in a more complex interactive setting.

To date, a considerable volume of studies have introduced the $\mathrm{TH}$ analytical method to investigate the pattern of non-linear interactions among institutional organizations such as universities, industries and governments (Choi et al., 2015; Hong and Su, 2013; Leydesdorff, 2003; Park and Leydesdorff, 2010; Phillips, 2014; Rho, 2014) and some literature analyzed how the living lab expands the boundary spanning between $\mathrm{TH}$ actors to achieve endogenous economic development (van Geenhuizen, 2016). After reviewing extant TH research, it is clear that the exploration of $\mathrm{TH}$ synergy and the quantification of $\mathrm{TH}$ relations have been the focus of current $\mathrm{TH}$ empirical studies (Choi et al., 2015; Leydesdorff and Meyer, 2006; Leydesdorff and Park, 2014). It should be noted that most literature only depicted the pattern of bilateral and trilateral relations between/among TH components (Yoon and Park, 2017), while a few studies attempted to explain the changes of $\mathrm{TH}$ relations by attributing them to S\&T policies issued by government (Park and Leydesdorff, 2010), and little effort was devoted to further clarifying the influence mechanism of TH interactions on the participants' performance. In addition, no work has provided a systematic evaluation on the TH relationships of IUR in China (Cai, 2014).

Extant TH literature usually labeled the research institutes as government sector when investigating the UIG interactions within the TH framework (Yang and Jung, 2016; Yoon and Park, 2017). This is largely due to the governmental nature of the research institutes as well as the availability of data sources for characterizing the $R \& D$ behavior of the research institutes. More specifically, in many countries such as China, the (public) research institutes, with significant governmental support, conduct high risk research in the public domain and develop public welfare technologies (Bozeman, 1987) as well as being directly guided by the government initiatives (Yoon, 2015). Given that the research institutes are founded and supervised by the government to pursue public interests, the R\&D behavior that the research institutes implement, to some extent, indicates the innovation efforts made by the government sectors (Yoon, 2015). Furthermore, the research institutes usually undertake some public management functions in the S\&T domain and are accordingly assigned to certain administrative grades in the bureaucratic system. Thus, the research institutes were to some degree deemed to be governmental agencies when UIG relations were 
investigated in TH studies (e.g., Belkhodja and Landry, 2007; Danell and Persson, 2003; Kwon et al., 2012; Leydesdorff and Meyer, 2010; Leydesdorff and Sun, 2009; Park et al., 2005; Park and Park, 2018; Park and Leydesdorff, 2010). Moreover, it is well known that the research institutes are the key actors in the S\&T domain (Bai, 2016) and their research outputs are usually the academic papers and patents, which can be easily retrieved from publication databases such as Scopus and Web of Science. The availability of data sources allows the researcher to make a quantitative characterization of the R\&D activities implemented by the governmental sector.

It is well known that the TH theory was initially grounded in Western developed countries. Some scholars hold a skeptical view that this theory may not be applicable to developing and emerging economies due to different national and local contexts (Eun et al., 2006; Williams and Woodson, 2012). In fact, the TH theory presents a general and flexible method for investigating the non-linear interactions or synergy among the innovation organizations from a dynamic perspective. This method has been widely adopted by the researchers to assess the dynamic interactions or synergy among universities, industry and governments in Asia, specifically in Korea (Park and Leydesdorff 2010; Khan and Park, 2011; Yoon, 2015) and Japan (Leydesdorff and Sun 2009; Sun and Negishi, 2010). Even so, the TH development in other Asian contexts (such as China) should be further explored. This would be beneficial to developing a benchmarking theoretical framework for understanding to what extent the TH model can be developed in different contexts, particularly the non-Western ones.

In this study, China's S\&T innovation system is taken as the research setting and the TH theory is adopted as the conceptual and empirical ground to study the evolutionary dynamics of innovation organizations within the national innovation systems, among which the research institutes, universities and industries play different roles and functions (Bai, 2016; Chen, 2017). Specifically, the non-profit public research institutes under the supervision of government usually devote efforts towards cutting-edge research in the S\&T domain (including big science infrastructure) and are committed to serving the major national S\&T needs (Bai, 2016). The universities are mainly engaged in freely explored research projects related to basic research, and the industry sector mainly focuses its efforts on applied research and technical development for product improvement (De Fuentes and Dutrenit, 2012). In this vein, the three institutional actors of IUR can be deemed to be three independent dimensions within the TH innovation system in China, which presents an ideal research setting for investigating the TH development model in the non-Western context. This allows the present study to introduce the TH analytical method to analyze the dynamic interactions or synergy among three innovation organizations in China, namely, industries, universities and research institutes. 
The TH interactions among IUR are generally defined as the boundary spanning across them (Champenois and Etzkowitz, 2017), forming an important channel for transferring knowledge and mobilizing resources (Meyer-Krahmer and Schmoch, 1998). So, the TH model of IUR relations can be conceptualized in terms of its components (i.e., research institutes, industries and universities), relationships (i.e., bilateral and trilateral interactions among them), and functions (i.e., the results of their activities). How to characterize the TH model of IUR relations and estimate whether the synergy of IUR interaction is generated or not? As Leydesdorff (2003) noted, the "synergy" results from an interaction effect among three institutional spheres that leads to the reduction of uncertainty within the TH innovation system. Accordingly, the value of the reduction of uncertainty can be treated as the indicator reflecting the level of synergy among innovation organizations. Based on this, Leydesdorff (2003) developed the mutual information or transmission $(T)$ indicator to examine the intensity of "overlaps" between/among dimensions by calculating the magnitude of mutual information that is transmitted between/among them. Since the $T$ indicator based on the concept of Shannon's information theory (Shannon, 1948; Shannon and Weaver, 1949) is flexible and general, it can be applied to quantitatively measure the TH relations among organizations without considering their roles and functions (Yoon and Park, 2017), so this indicator has been adopted by extant literature to characterize the dynamics of bilateral and trilateral interactions or collaborative synergy among different dimensions in the TH innovation system (Ivanova and Leydesdorff, 2014a, 2014b; Leydesdorff and Zhou, 2014). However, the $T$ indicator measuring mutual information between dimensions is subject to a limitation as it degenerates into a puzzle of the alternating sign of the mutual information in more than two dimensions. This inspires Leydesdorff and Ivanova (2014) to solve this technical puzzle by introducing the mutual redundancy $(R)$ indicator, which ensures that the sign of the value for characterizing TH relational interactions remains consistent. The $R$ indicator has been introduced by following studies (Leydesdorff and Ivanova, 2016; Leydesdorff et al., 2017) for measuring the synergy in innovation systems. More recently, Mêgnigbêto (2018b) introduced game theory indicators to measure the synergy within the TH innovation system. In summary, previous studies have made substantial contributions to the development of TH theory and analytical method (e.g., Leydesdorff, 2003, 2018; Leydesdorff and Ivanova, 2014; Leydesdorff and Sun, 2009; Park et al., 2005; Park and Leydesdorff, 2010), which act as a substantial theoretical base for this empirical research.

\subsection{Hypotheses development}


Previous studies have confirmed that the free flow of knowledge and ideas within innovation systems is crucial for sustainable S\&T development in a national or regional system (Park and Leydesdorff, 2010). The topic of knowledge creation and transferring has attracted more and more attention in recent years (Biscaro and Comacchio, 2018; Lee et al., 2018; Miller et al., 2016; Rau et al., 2016). It is widely acknowledged that knowledge creation and transferring more likely appear on the interfaces of interactions between different organizations (Alexander et al., 2016; Azagra-Caro et al., 2017). This can be explained by the TH theory which emphasizes the interdependence and interactions between heterogeneous innovation organizations to create, transfer and internalize knowledge, thereby creating a knowledge-based economy (Alexander et al., 2016).

Since the knowledge creation and transferring are a critical antecedent for successful innovation (Anatan, 2018; Rau et al., 2016), and the interactions among innovation organizations can stimulate knowledge creation and transferring across boundaries (Azagra-Caro et al., 2017; Park and Leydesdorff, 2010), it is easy to deduce that the bilateral and trilateral interactions between/among research institutes, industries and universities would positively influence the participants' performance. Moreover, according to the knowledge-production function introduced by Griliches (1979), it is widely assumed that research investments, including the amount of professional researchers and research funds, have a positive impact on scientific performance (Griliches, 1979). This raises an interesting question whether the bilateral and trilateral interactions have a promoting effect on the relationship between research investments and scientific performance. In fact, it is reasonable to expect that the $\mathrm{TH}$ interactions among research institutes, industries and universities may not only exert a direct positive effect on the participants' performance but also have a positive moderating effect on the relationship between the research investments and the performance of participants. The reasons are presented as follows.

The research interactions between innovation organizations facilitate knowledge flows across partners (Azagra-Caro et al., 2017; Gomes-Casseres et al., 2006), and the knowledge transfer increases the chances for mutual learning that stimulates new knowledge creation, which thereby contributes to improving scientific performance (Tsai, 2001). In addition, as Leydesdorff and Ivanova (2016) noted, the "overlaps" between innovation organizations can add more redundancy (new options) to the system, which indicates that the innovation organizations on the interfaces can consider the same thing from different perspectives and, thereby generate more research options or strategies. This is crucial for new knowledge production and performance improvement (Leydesdorff et al., 2017). So, the redundancy (overlap) generated by the TH interactions among innovation organizations can be deemed as a source of innovations (Leydesdorff et al., 2017). In this vein, it is 
reasonable to anticipate that a direct effect that $\mathrm{TH}$ interactions exert on the scientific performance is positive. As such, the first hypothesis is presented as:

Hypothesis 1: The TH interactions among innovation organizations such as research institutes, industries and universities have a positive impact on the participants' scientific performance.

Although research investments are an important antecedent of performance improvement (Griliches, 1979), their impacts on participants' performance may depend on the extent to which the innovation organizations involve in TH interactions with others. Why? In fact, the TH interactions endow an organization with the privilege of access to complementary knowledge from its partners (Paruchuri, 2010), and hence expand its knowledge resources and enhance its innovative ability (Lee and Kim, 2016). Thus, by TH interactions, the organization could tap into external knowledge sources and exploit the research investments more efficiently, which in turn enhance its research performance (Berchicci, 2013). On the contrary, even though an organization obtains certain research investments, its performance may not be efficiently enhanced if it does not form close linkages with other organizations. This is due to the fact that an organization kept away from interactions with others may confront many obstacles of knowledge transfer, which thereby results in a poor R\&D capability and further lowers the transformation efficiency from research inputs to outputs.

Since the TH interactions among innovation organizations can realize resource sharing and advantageous complementarities, inspire new ideas and result in better efficiency of $R \& D$ input-output processes, it is reasonable to deduce that the innovation organizations involving in $\mathrm{TH}$ interaction are more likely to have higher performance than those staying away from TH interactions given the same conditions of research investments. In other words, the impact of research investment on scientific performance would be enhanced by the TH interactions. Hence, the second hypothesis is presented as:

Hypothesis 2: The TH interactions among innovation organizations such as research institutes, industries and universities positively moderate the relationship between the research investments and the scientific performance of participants.

\section{Methodology}

\subsection{Research setting and data collection}

In this study, China's S\&T innovation system is taken as the research setting and the impacts of the TH interactions among three innovation organizations (that is, research institutes, industries and universities) are investigated. Specifically, the largest public research institute in China, namely, CAS directly supervised by the China State Council, is chosen and its bilateral/trilateral interactions 
with industries or/and universities are used as the research sample to test these hypotheses. There are three reasons for the choice.

Firstly, the TH interactions among research institutes, industries and universities are expected to play an increasingly important role in China, which is largely due to the unique characteristics of China's S\&T innovation systems (Liu and White, 2001). In China, the research institutes have stronger R\&D power and possess more innovation resources compared with other innovation organizations (Zhang et al., 2016). The policy makers have tried to create effective institutional arrangements to encourage research institutes to form research linkages with industries and universities, among which the CAS is one key player (Zhang et al., 2016).

Secondly, the CAS, as the most typical research institute in China, focuses on scientific research. Over 85 percent of China's large-scale science facilities are concentrated in the CAS. It has the nation's largest research team consisting of about 67,900 staff, among which 82.6 percent are professional personnel. A majority of scientific elites in China are now working or have worked in CAS. In terms of the Global Nature Index presented by the nature publishing group, the CAS has been ranked the first in the world for the past several years (2012-2017). Apart from some unique characteristics that the CAS demonstrates, it also displays some common features within the group of research institutes. For example, like other research institutes, the CAS mainly engages in basic and applied research that addresses specific national needs and challenges. Accordingly, the research institutes, particularly the CAS, are expected to become the engines of economic development and competitiveness by promoting knowledge transfer and innovation in research collaboration with industries as well as universities (Zhang et al., 2016). In this vein, some research findings from CAS can be generalized to other research institutes.

Thirdly, the CAS has assumed the crucial role in enhancing research interactions with industries and universities since it was set up in 1949. In the era of planned economy (1949-1978), the CAS was an important member that collaborated with industries and universities in the research of "two atomic bombs and one satellite" (Liu and Zhi, 2010; Liu and White, 2001). In 1992, the CAS was one of the promotors in "the joint development project of IUR" launched in 1992. When the "Pioneer Initiative" and "Innovation 2020" were implemented in recent years, the CAS was requested to strengthen the linkages with the industries and universities in research collaboration and technology transfer.

Since the CAS has been making efforts and taking many actions to drive and participate in IUR interactions over the years, some explorations into bilateral/trilateral interactions of CAS with industries or/and universities can contribute to shedding important insights into $\mathrm{TH}$ innovation systems in China. Meanwhile, the bilateral/trilateral relationships of CAS with industries or/and 
universities form an appropriate context for examining the effects of $\mathrm{TH}$ interactions on the participants' performance because they are the typical innovation actors within the TH innovation system and thus the research findings based on this context can be generalized to other research settings.

A basic problem in this study is the collection of data for describing the $\mathrm{TH}$ interactions of the CAS with industries and universities in the scientific research field. How can the information embodying the bilateral and trilateral relationships of the CAS with industries and/or universities be collected? Note that the CAS is mainly engaged in scientific research (Zhang et al., 2016), and this study is focused on the CAS's TH interactions with industries and universities in the scientific research field. Moreover, the co-authorship of publications, as the most visible indicator of scientific collaboration (Mêgnigbêto, 2018b), has been widely used as a proxy for measuring TH relationships (e.g., Mêgnigbêto, 2018b; Park and Leydesdorff, 2010). This methodology is also adopted by the present study for examining the CAS's bilateral and trilateral interactions with industries and universities in the scientific research field.

In several types of literature records, those indexed in the Science Citation Index Expanded (SCIE) database, indexing the main Chinese authoritative science journals, are an appropriate choice because of the natural science property of the CAS's research activities as well as the increasing tendency of publishing the CAS's research findings in international journals. Note that using the co-authored SCIE papers by CAS with industries or/and universities as the data source for measuring the TH relationships among them has some limitations, which will be discussed in a later section. However, the co-author publications have been widely used and validated as a valuable proxy for these relationships despite having these limitations (Park and Leydesdorff, 2010), because they can provide the basic, useful, and effective information of the scientific interactions among the innovation organizations. So, more and more scholars have used the co-author relationships to explore the bilateral and trilateral interactions among different organizations in the TH system (e.g., Leydesdorff and Sun, 2009; Park and Leydesdorff, 2010; Park and Park, 2018; Ye et al., 2013). This study follows extant literature and uses the co-authored SCIE papers by CAS with industries or/and universities as the data source for exploring the $\mathrm{TH}$ interactions among them. By adopting the search strategy proposed by Chen et al. (2017) and Zhang et al. (2016), this study conducted the retrieval processes on February 20, 2017. The time span of data is confined to 1984-2016.

\subsection{Mutual redundancy indicator}


A large amount of extant studies have adopted the information transmission indicator, namely, $\mathrm{T}$ value, to measure the amount of mutual information between/among dimensions (Park and Leydesdorff, 2010; Ivanova and Leydesdorff, 2014a, 2014b, 2014c; Leydesdorff and Zhou, 2014). In this way, the extent to which the dynamic interactions between/among institutional actors in the $\mathrm{TH}$ innovation system can be characterized quantitatively (Yoon and Park, 2017).

Based on the probabilistic entropy theory (Shannon, 1948; Shannon and Weaver, 1949; Abramson, 1963), Leydesdorff (2003) proposed the equations for measuring the mutual information generated by the "overlaps" between/among two or three dimensions $i, j$ and $l$, which are presented as follows:

$$
\begin{gathered}
T_{i j}=H_{i}+H_{j}-H_{i j} \\
T_{i j l}=H_{i}+H_{j}+H_{l}-H_{i j}-H_{i l}+H_{j l}+H_{i j l}
\end{gathered}
$$

In Equations (1) and (2), $H_{i}, H_{i j}$ and $H_{i j l}$ are probabilistic entropies and their values refer to the uncertainty that prevails in one, two and three distributions, respectively. They are measured by $H_{i}=-\sum_{i} P_{i} \log _{2}\left(P_{i}\right), \quad H_{i j}=-\sum_{i} \sum_{j} P_{i j} \log _{2}\left(P_{i j}\right)$ and $H_{i j l}=-\sum_{i} \sum_{j} \sum_{l} P_{i j l} \log _{2}\left(P_{i j l}\right)$, respectively, where $P_{i}, P_{i j}$ and $P_{i j l}$ refer to probability that the random message (event) is selected within a system (Shannon, 1948; Shannon and Weaver, 1949; Abramson, 1963).

According to previous studies (Ivanova and Leydesdorff, 2014c; Park and Leydesdorff, 2010), the $\mathrm{T}$ value can be used to represent the level of $\mathrm{TH}$ interactions within an innovation system. However, the $\mathrm{T}$ value demonstrates an inconsistent sign between the odd-dimensional cases and the even-dimensional ones. For example, the $\mathrm{T}$ value in the two-dimensional case, which can be calculated by Equation (1), is usually positive, whereas the T value in the three-dimensional case, which can be calculated by Equation (2), is necessarily negative. This alternating sign of $\mathrm{T}$ value is likely to generate a puzzle whether the TH interaction between/among two or more dimensions is enhanced or declined. To cope with this limitation, Leydesdorff and Ivanova (2014) developed an alternative indicator, namely, the mutual redundancy $(\mathrm{R})$ indicator, to ensure that the sign of the indicator for depicting the TH interactions remains consistent.

As Leydesdorff and Ivanova (2014) noted, the mutual redundancy can be considered as a consequence of the "overlaps" between/among two or more dimensions. Since the overlapping information is counted repeatedly when the probabilistic entropies are measured, the "overlaps" between/among two or more dimensions can be deemed as redundancy that reduces the uncertainty prevailing in the system. In this vein, the mutual redundancy can reflect the level of relational interaction between/among two or more dimension. 
According to Leydesdorff et al. (2017), the equation for calculating the mutual redundancy between/among two or more dimensions is written as follows:

$R_{n}=\left[H\left(x_{1}, \ldots, x_{n}\right)-\sum_{1}^{n} H\left(x_{i}\right)\right]+\left[\sum_{i j}^{\left(\begin{array}{c}n \\ 2\end{array}\right)} T_{i j}-\sum_{i j l}^{\left(\begin{array}{c}n \\ 3\end{array}\right)} T_{i j l}+\sum_{i j l k}^{\left(\begin{array}{c}n \\ 4\end{array}\right)} T_{i j l k}-\cdots+(-1)^{1+n} \sum_{i j l k \ldots(n-1)}^{\left(\begin{array}{c}n \\ n-1\end{array}\right)} T_{i j l k \ldots(n-1)}\right]$

Based on the generalized Equation (3) discussed above, it is easy to deduce the equations, which have been stated in Leydesdorff and Ivanova (2014), for calculating the mutual redundancy between/among two or three dimensions $\mathrm{i}, \mathrm{j}$ and $\mathrm{l}$, which are also written as follows:

$$
\begin{gathered}
R_{i j}=H_{i}+H_{j}+H_{i j}-2 T_{i j}=-T_{i j} \\
R_{i j l}=H_{i}+H_{j}+H_{l}-\left(H_{i j}+2 T_{i j}\right)-\left(H_{i l}+2 T_{i l}\right)-\left(H_{j l}+2 T_{j l}\right)+\left(H_{i j l}+2 T_{i j}+2 T_{i l}+2 T_{j l}\right)=T_{i j l}
\end{gathered}
$$

In Equations (4) and (5), the mutual redundancy R is necessarily negative (Leydesdorff et al., 2017; Leydesdorff and Ivanova, 2014). This suggests that more prevailing uncertainties are reduced in the system when the relational interactions between/among two or more dimension are significantly enhanced.

\subsection{Variables}

\subsubsection{Dependent variable}

As mentioned earlier, the CAS is China's largest research institute (academic sector) mainly engaging in scientific research and often publishing research findings in international journals, thus the typical research output of the CAS is SCIE literature (Zhang et al., 2016). This study is focused on the TH interactions among CAS, industries and universities in the scientific research field, and their interactions likely lead to a number of research outcomes among which the co-authored literature is an important one (Laudel, 2002). Moreover, the academic publications, especially the SCIE literature, are the most accepted proxy for scientific performance (Banal-Estanol et al., 2015; Gonzalez-Brambila et al., 2013). Therefore, this study uses the amount of SCIE literature produced by CAS as proxy for its scientific performance.

\subsubsection{Explanatory variables}

Due to the limitation of inconsistent sign of the $T$ value between the odd-dimensional cases and the even-dimensional ones, this study follows previous literature (Leydesdorff et al., 2017; Leydesdorff and Ivanova, 2014, 2016) and adopts the " $R$ value" rather than the " $T$ value" to depict the TH interactions among CAS, industries and universities. According to Leydesdorff and Ivanova 
(2014), the synergy in a TH innovation system can be considered as the result of an overlay of exchange between/among TH distributions. In this vein, the level of TH interactions or synergy can be quantified. Specifically, the mutual redundancy ( $R$ value) generated by the relational interactions between/among TH distributions can be used for characterizing the dynamics of bilateral and trilateral relational interactions or collaborative synergy among them.

Therefore, three types of $R$ values in this study, namely, $R$ value $(C I), R$ value $(C U)$ and $R$ value $(C I U)$, are adopted to represent the level of TH-type interactive relations between/among CAS-Industry, CAS-University, and CAS-Industry-University, respectively. If $R$ value $<0$, the prevailing uncertainty is reduced among the overlapping dimensions, indicating that couplings among CAS, industries and universities within the TH innovation system are found.

$R$ value $(C I)$. This variable refers to the amount of mutual redundancy resulting from the overlapping configurations between CAS and industries, which indicates the intensity of bilateral interactions between them. This variable can be calculated using the Equations (1) and (4) in Section 3.2 .

$R$ value $(C U)$. This variable refers to the amount of mutual redundancy resulting from the overlapping configurations between CAS and universities, which reflects the intensity of bilateral interactions between them. This variable can be calculated using the Equations (1) and (4) in Section 3.2 .

$R$ value $(C I U)$. This variable stands for the amount of mutual redundancy resulting from the overlapping configurations among CAS, industries and universities, which indicates the level of synergy within the TH system. This variable can be calculated using the Equations (2) and (5) in Section 3.2.

\subsubsection{Control variables}

Pre-sample SCIE literature. This variable reflects the past research experience and capacity of the CAS in scientific activities, which should be controlled because it likely influences the CAS's scientific performance. This study follows Blundell et al. (1995) and estimates this variable as the sum of SCIE literature produced by the CAS in the 5 years prior to their entry into the sample, as shown by Equation (6).

$$
P R_{t}=\sum_{i=1}^{5} S C I E_{t-i},
$$

where $S C I E_{t-i}$ is the number of SCIE indexed papers published by CAS in the year $t-i$. 
Professional researchers. This variable refers to the number of full-time basic researchers working for the CAS, which is an important factor influencing scientific activities (Griliches, 1979) and should be controlled. The data can be obtained from the annual report of the CAS.

Research funds. This variable refers to the various spending directly related to the basic research activities in the CAS. According to Griliches (1979), the research funds as part of research investments have significant impacts on the CAS's scientific performance and should be controlled. The data can be obtained from the annual report of the CAS.

The data of basic research investments of the CAS after 1995 are collected because other data from1995 and earlier years are not provided by the CAS (see such previous studies as Zhang et al., 2011). To keep the time span of all variable consistent in subsequent regression models for testing hypotheses, the time period for measuring all variable ranges from 1996 to 2016. To eliminate the heteroskedasticity and volatility, this study follows previous literature such as Laursen et al. (2011) and makes a log transformation for these control variables.

\subsection{Examination model}

The dependent variable, as the countable data, takes only a non-negative integer value and exhibits an over-dispersed feature. Because the distribution of residuals is heteroskedastic non-normal, the linear regression model is not appropriate for modeling such variables. The Poisson regression approach may be appropriate to model count data, but it is based on the assumption that the mean of the data is equal to the variance (Demidenko, 2013). Since the countable data have an over-dispersion problem and the variance certainly exceeds the mean, using the negative binomial model as an extension of the Poisson model (Baba et al., 2009; Cameron and Trivedi, 2013) is more suitable. Previous studies (Chen et al., 2017; Fleming et al., 2007; Guan et al., 2015; Schilling and Phelps, 2007) have employed the negative binomial model for related studies in which the dependent variables are the countable data.

In this study, the negative binomial model is employed to estimate the models step by step in different scenarios. Moreover, the suitable lag structure of the independent variables is another estimation issue. To enhance the robustness of the regression results, this study follows extant literature (Chen et al., 2017; Guan and Zhao, 2013; Schilling and Phelps, 2007) and evaluates the model by, respectively, considering one-year lag, two-year lag, three-year lag and the average value over three lagging years on the scientific performance of the CAS. The model is estimated by using STATA 15.1 software. 


\section{Results}

\subsection{The dynamic patterns of TH interactions among CAS, industries and universities}

In this section, the bilateral and trilateral interactions between/among CAS, industries and/or universities are retraced by using the $R$ indicators, which are based on mutual redundancy measured in mbits. Figure 1 displays the estimated $R$ values for CAS-University (on the left y-axis) and CAS-Industry (on the right $\mathrm{y}$-axis), and Figure 2 illustrates the produced $R$ value for CAS-Industry-University. As shown in Figures 1 and 2, all of $R$ value (CU), $R$ value (CI) and $R$ value (CIU) are negative and mainly display a declining trend (or, in other words, become more negative) over the whole period. According to Leydesdorff and Ivanova (2014, 2016), the more negative $R$ value indicates more reduction of uncertainty between/among two/three dimensions, which is an indicator of the synergetic effect of TH relations. Thus, the declining trend demonstrates that there is an increase in mutual interactions among the $\mathrm{TH}$ sectors of the CAS, industries and universities, and their TH relations become more synergetic over time.

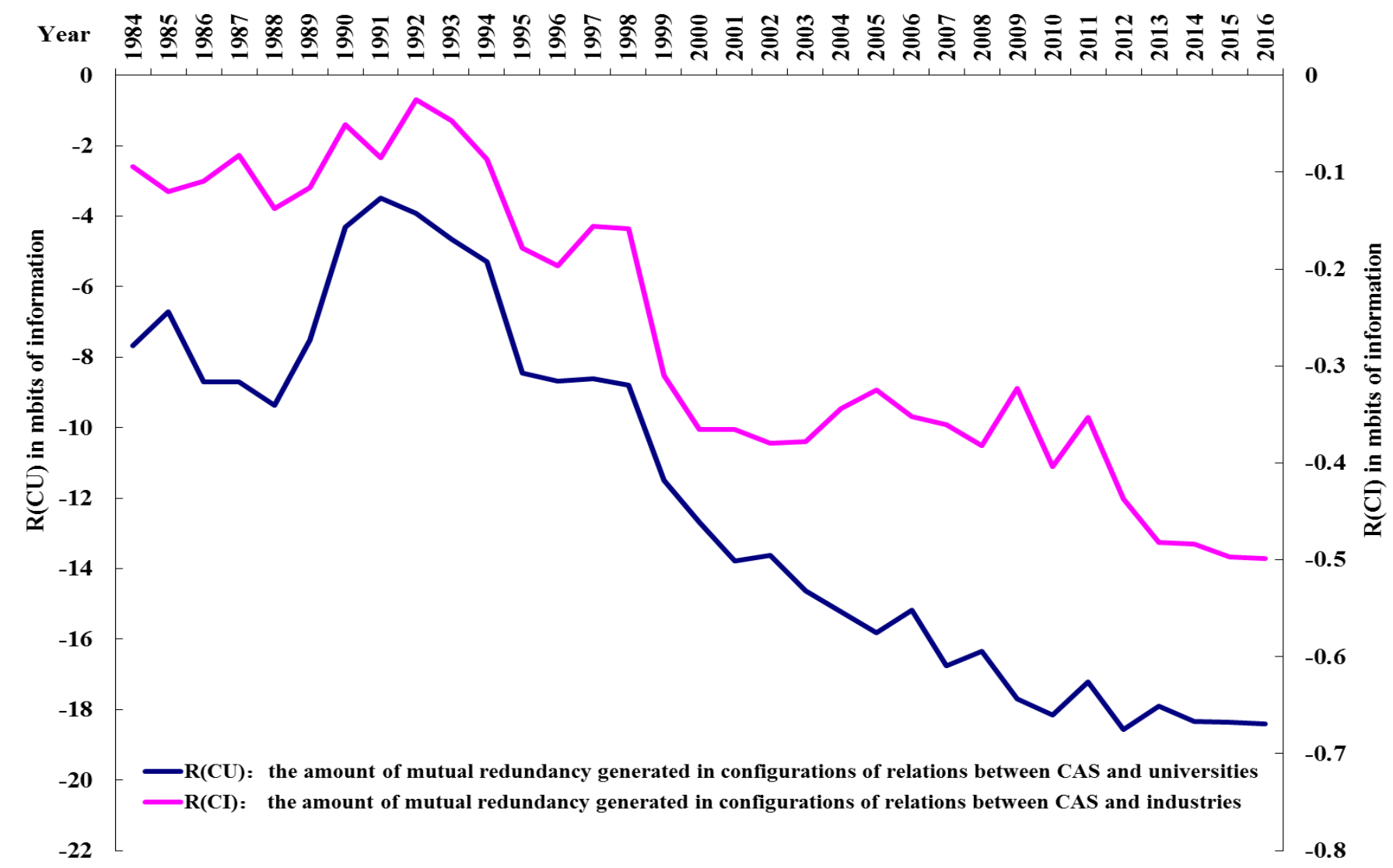

Figure 1: The mutual redundancy resulting from the overlapping configurations between two groups:

\section{CAS-Industry and CAS-University}


As shown in Figure 1, except for some years before the early 1990s, both $R$ value (CU) and $R$ value (CI) became more and more negative. This indicates the mutual redundancy increasing in absolute value. In other words, the dynamic interactions of CAS-Industry and that of CAS-University have been continually enhanced. It should be noted that the $R$ value (CU) (on the left y-axis) is much lower than the $R$ value (CI) (on the right y-axis). This indicates that the bilateral interactions between CAS and universities are more prominent than those between the CAS and enterprises. This is partly due to the difference in the objectives, incentives, values and cultures between academic institutes and industry sectors (Kafouros et al., 2015). The academic institutes focus on generating and publishing research findings, while the industry sectors commonly seek economic value rather than publishing academic papers (Bruneel et al., 2010). Besides, the poor internal R\&D capability of domestic enterprises (Motohashi and Yun, 2007; Perks et al., 2009) is another important factor for hampering CAS-Industry interactions.

In terms of the evolution trend, both $R$ value $(\mathrm{CU})$ and $R$ value $(\mathrm{CI})$ run in the opposite direction during the period of 1988 and 1991 compared with other years. The increasing differentiation (uncoupling) between CAS-Industry and CAS-University may be attributed to the influence of an unstable political environment at home and abroad. However, something changed in 1992, when the Chinese government launched the "Joint Development Project of IUR" to promote the linkages among three institutional actors: universities, industries and research institutes (Sun and Cao, 2015). Since then, the bilateral interactions between the CAS and universities have been continually enhanced. In contrast, the CAS-Industry interactions were still weaker than the CAS-University interactions throughout the period 1984-2016 even though a series of S\&T policies have been issued by the government to promote these interactions. Moreover, it should be noted that the $R$ value (CU) displayed a more stable decline, in contrast to the gentle trend of the $R$ value $(\mathrm{CI})$ during the more recent 15 years, which suggests that China's industry sectors with poor R\&D capacities were reluctant to participate in the scientific interactions with academic institutes. This differs significantly from developed countries where scientific participation by the industry sector has become a prevalent behavior (Choi et al., 2015). 


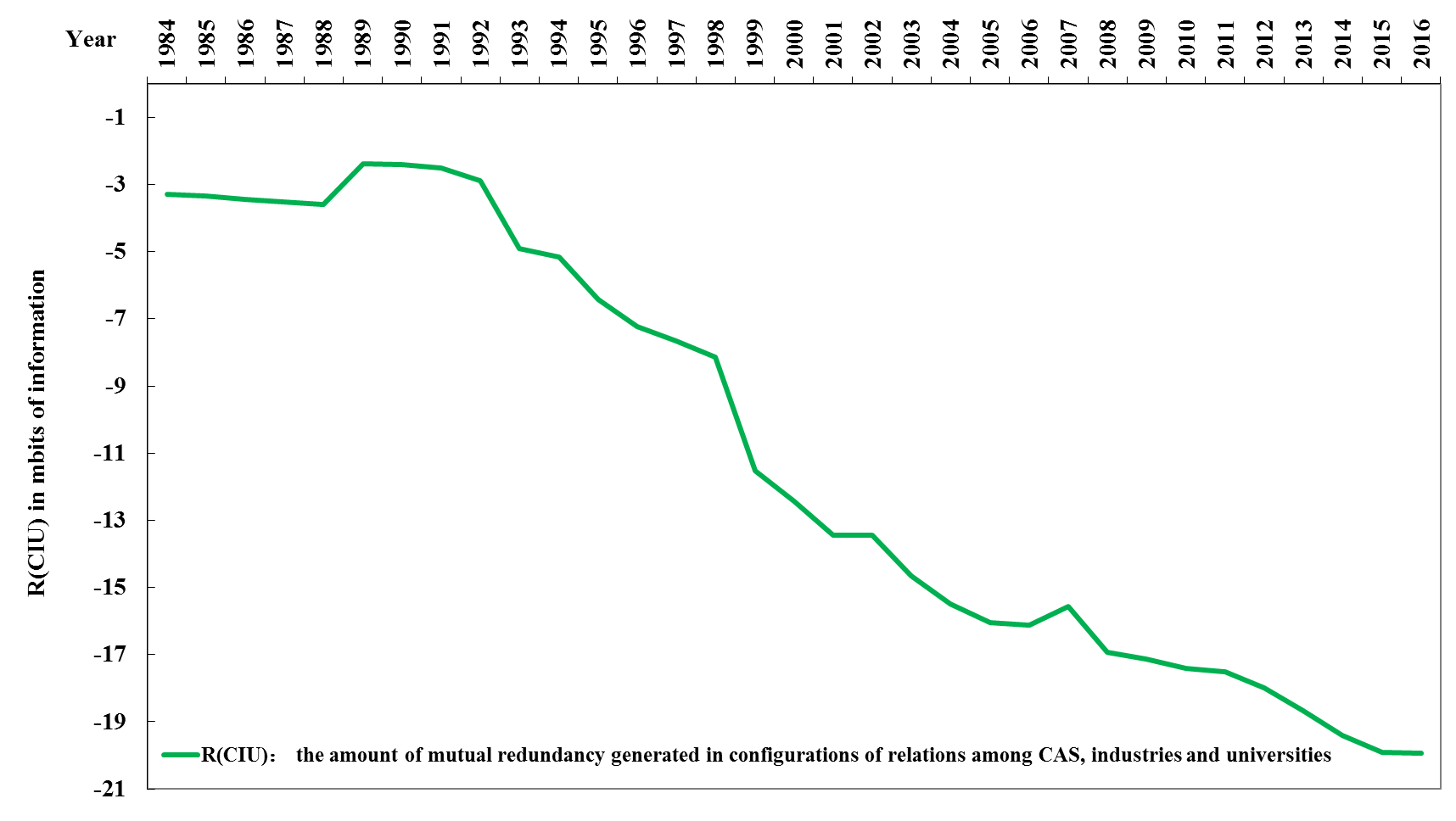

Figure 2: The mutual redundancy resulting from the overlapping configurations among three groups: CAS-Industry-University

The result presented in Figure 2 is interesting, as it reveals the major developing trend of the $R$ value (CIU) in accordance with the issue of China's key S\&T policies for enhancing the IUR synergy during the last three decades. This endows the present study with an opportunity for examining the guiding role of China's S\&T policies for shaping the TH interactions among three innovation organization: CAS, industries and universities. First, $R$ value (CIU) declined slowly during the period 1984-1988, which indicates that the synergetic effect of trilateral relations among CAS, industries and universities were remarkable. Since China's reform and opening-up in the late 1970s, the Chinese government has maintained the belief that S\&T development is the foundation of national competitiveness. The reform of the S\&T innovation system was implemented in 1985 . In this circumstance, the spontaneous interactions among the CAS, industries and universities became a regular occurrence. Second, the $R$ value (CIU) ran in the opposite direction during the period 1989-1992, suggesting the uncoupling trend appeared among three groups of CAS-Industry-University. As mentioned previously, the unstable political environment at home and abroad during this period may have interrupted the synergy among CAS, industries and universities. Third, the $R$ value (CIU) displayed a declining trend since 1992. One possible reason for this change is that the "Joint Development Project of IUR" was implemented, which promoted trilateral interactions among the research institutes, industries and universities (Huang and Yuan, 2014; Sun and Cao, 2015). Fourth, the $R$ value (CIU) has declined rapidly since 1998, which may be ascribed to the "Knowledge Innovation Program (The First Phase)" launched by the CAS that advocated mutual 
interactions with universities and industries. The "Knowledge Innovation Program (The Second Phase)" was launched in 2011, which further promoted CAS-Industry-University relations. Fifth, the "National Outline for Medium- and Long-term Education Reform and Development Plan (2010-2020)" was launched, which specified that universities should interact with industries to serve social and economic development in China (Liu et al., 2011). Finally, the "Pioneer Initiative" and "Innovation 2020" were implemented by CAS in recent years, which provoked the open model of research activities through the interactions with universities and industries to meet the requirement of serving social and economic development in China. In summary, the S\&T policies played a critical role in promoting CAS-Industry-University synergy during the entire period (1984-2016).

\subsection{The impacts of the TH interactions among CAS, industries and universities}

In order to further reveal how the TH interactions influence the research institutes' scientific performance, the TH systems of CAS with industries and universities are taken as the research setting to test the hypotheses discussed in Section 2. The regression analysis is performed to empirically investigate the following topics: (1) whether the $\mathrm{TH}$ interactions among the CAS, industries and universities are beneficial to the CAS's scientific performance; (2) whether the relationship between the research investments and the scientific performance of CAS is positively moderated by the TH interactions among the CAS, industries and universities.

The descriptive statistics for the variables and their correlation analysis results are illustrated in Table 1. Clearly, the high correlation among explanatory variables is quite alarming. This indicates that there may be multi-collinearity problems that should not be overlooked. However, according to the argument of Blais (2003), the discriminant validity is acceptable when all the correlation coefficients between the explanatory variables are less than the threshold value 0.7. As shown by Table 1, it is clear that all the correlations among explanatory variables in this study fall below the threshold value (0.7) and the largest one is only 0.556. Even so, this study carries out a robustness check by calculating the variance inflation factors (VIFs) of explanatory variables (Anand et al., 2010). The result shows that all VIFs are below 10 (the largest one is 7.19). Thus, according the rule presented in Belsley (2005) and Blais (2003), the multi-collinearity does not seem to be a problem in this research (see such previous studies as Chen et al., 2017).

Table 1. Descriptive statistics and correlational statistical analysis

\begin{tabular}{|c|c|c|c|c|c|c|c|c|c|c|c|}
\hline & Min & $\operatorname{Max}$ & Mean & S.D. & 1 & 2 & 3 & 4 & 5 & 6 & 7 \\
\hline 1.The number of SCIE literature & 4038 & 53889 & 24613 & 25134 & 1.000 & & & & & & \\
\hline 2.R value $(\mathrm{CI})$ & -0.45 & -0.156 & -0.342 & -0.076 & -0.237 & 1.000 & & & & & \\
\hline
\end{tabular}




\begin{tabular}{lllllllllllll}
\hline 3.R value $(\mathrm{CU})$ & -18.588 & -8.609 & -14.230 & -2.985 & -0.501 & 0.529 & 1.000 & & & & \\
4.R value (CIU) & -18.015 & -7.241 & -13.944 & -3.357 & -0.460 & 0.412 & 0.556 & 1.000 & & & & \\
5.Pre-sample SCIE literature [ln] a & 9.207 & 12.113 & 10.890 & 0.884 & 0.550 & -0.294 & -0.416 & -0.415 & 1.000 & & \\
${\text { 6.Professional researchers }[\mathrm{ln}]^{\mathrm{a}}}$ & 9.296 & 10.215 & 9.624 & 0.219 & 0.107 & -0.320 & -0.464 & -0.522 & 0.405 & 1.000 & \\
7.Research funds [ln] $^{\mathrm{a}}$ & 1.929 & 4.916 & 3.311 & 0.801 & 0.449 & -0.518 & -0.513 & -0.403 & 0.456 & 0.507 & 1.000 \\
\hline
\end{tabular}

${ }^{\text {a }}$ The natural logarithm of a variable is denoted by suffix [ln].

The regression results for the direct impact of the TH interactions ( $R$ value) on the scientific performance of the CAS are summarized in Table 2. Overall, the Log likelihood values show that the models in Table 2 are robust, which means that the negative binomial models have high goodness-of-fit. Moreover, the regression results (including the signs of coefficients and the levels of significance) are consistent and stable across regression models in Table 2, which indicates that these regression results are also robust.

Based on the Models 1, 5, 9 and 13 in Table 2, it is clear that $R$ value (CI) demonstrates a negative and statistically significant influence on the scientific output of the CAS, suggesting that the more reduced uncertainties in the overlapping dimensions of CAS and industries (i.e., mutual redundancy) contribute to the more knowledge production. In other words, the bilateral interactions between the CAS and industries are beneficial to the CAS's scientific performance. This result is not surprising as the bilateral interactions mean that the participants are better able to pool valuable information and to exploit complementary assets, and this results in better scientific productivity (Callaert et al., 2015). In the Models 2, 6, 10 and 14, $R$ value (CU) also exhibits a negative and statistically significant effect, indicating that the more reduced uncertainties between CAS and universities result in the more knowledge production. In other words, the more interactions the CAS has with universities, the better the scientific performance the CAS achieves. By comparing $R$ value (CU) with $R$ value (CI) in term of the significance of their coefficients, it is clear that the bilateral interactions between CAS and universities exhibit a more significant beneficial effect compared with the bilateral interactions between CAS and industries. This is consistent with the earlier finding that CAS-Industry interactions are weaker than CAS-University interactions, and confirms the arguments of Lavie and Drori (2012) that the inter-organizational interaction is an efficient tactic for promoting research capability, especially for the academic research units in developing countries with limited resources. From the Models 3, 7, 11 and 15, one can learn that the coefficients for $R$ value (CIU) is negative and highly statistically significant, which indicates that the TH synergy among the CAS, industries and universities significantly enhances the scientific performance of the CAS. This is not surprising because prior researchers have shown that the research interactions among heterogeneous actors benefit scientific production by generating new ideas, motivating new research projects 
(Perkmann and Walsh, 2009), providing an efficient way to access additional or complementary resources and speeding up the research process (e.g., Katila and Mang, 2003; Zhao et al., 2015). In addition, the regression results of Models 4, 8, 12 and 16 show that the simultaneous effects of $R$ value (CI), $R$ value (CU) and $R$ value (CIU) are consistent with those in the independent regressions above with regard to the signs of coefficients as well as the levels of significance when the effects of other variables such as pre-sample SCIE literature, research funds and professional researchers were controlled.

Regarding the control variables, pre-sample SCIE literature has positive and significant effects on the scientific outputs of the CAS. This is consistent with the findings of Guan et al. (2015), Guan and Zhao (2013) and Schilling and Phelps (2007) that the previous knowledge base is always positively associated with research outputs. Besides, research funds and professional researchers have positive and significant effects on the scientific outputs of the CAS. This confirms the importance of research investments in strengthening scientific performance, which has been proved by Griliches (1979). In summary, the above analyses confirm that the scientific performance of the CAS is positively affected by its involvement in the TH interactions with industries and universities. Thus, Hypothesis 1 receives support. 
Table 2. The negative binomial regression models for the direct effect of $\boldsymbol{R}$ value

\begin{tabular}{|c|c|c|c|c|c|c|c|c|}
\hline & \multicolumn{4}{|c|}{$\begin{array}{l}\text { The number of SCIE literature published by the CAS } \\
\qquad(\mathrm{t}+1)\end{array}$} & \multicolumn{4}{|c|}{$\begin{array}{l}\text { The number of SCIE literature published by the CAS } \\
\qquad(\mathrm{t}+2)\end{array}$} \\
\hline & Model 1 & Model 2 & Model 3 & Model 4 & Model 5 & Model 6 & Model 7 & Model 8 \\
\hline 1.R value $(\mathrm{CI})$ & $-0.2936^{*}$ & & & $-0.2691^{*}$ & $-0.4592^{*}$ & & & $-0.4011^{*}$ \\
\hline 2.R value (CU) & & $-0.0174^{* *}$ & & $-0.0136^{* *}$ & & $-0.0293^{* * * *}$ & & $-0.0260^{* * * *}$ \\
\hline 3.R value (CIU) & & & $-0.0206^{* *}$ & $-0.0172^{* *}$ & & & $-0.0191^{* *}$ & $-0.0167^{* *}$ \\
\hline 4.Pre-sample SCIE literature $[\ln ]^{\mathrm{a}}$ & $0.5022^{* * * *}$ & $0.5039^{* * *}$ & $0.4130^{* * *}$ & $0.4012^{* * * *}$ & $0.3477^{* * *}$ & $0.4401^{* * *}$ & $0.3372^{* * *}$ & $0.3125^{* * *}$ \\
\hline 5.Professional researchers $[\ln ]^{\mathrm{a}}$ & $0.0871^{*}$ & $0.0915^{* *}$ & $0.1053^{*}$ & $0.0850^{*}$ & $0.0816^{*}$ & $0.0728^{*}$ & $0.0658^{*}$ & $0.0738^{* *}$ \\
\hline 6.Research funds $[\ln ]^{\mathrm{a}}$ & $0.2127^{* * * *}$ & $0.2309^{* * *}$ & $0.2077^{* * * *}$ & $0.1858^{* * * *}$ & $0.3278^{* * * *}$ & $0.3646^{* * *}$ & $0.3635^{* * *}$ & $0.3344^{* * * *}$ \\
\hline Constant & $0.6433^{* *}$ & $0.5659^{* *}$ & $0.7310^{* *}$ & $0.8725^{*}$ & $0.5801^{* *}$ & $0.4580^{*}$ & $0.4235^{* *}$ & $0.5122^{*}$ \\
\hline Wald chi2 & 2350.08 & 2230.58 & 2297.44 & 3282.12 & 2996.32 & 2843.37 & 2605.06 & 3356.23 \\
\hline Log likelihood & -123.8262 & -119.2322 & -120.0132 & -118.4633 & -111.4332 & -111.5022 & -112.0250 & -109.8928 \\
\hline \multirow[t]{2}{*}{ Probe $>$ chi 2} & 0.0000 & 0.0000 & 0.0000 & 0.0000 & 0.0000 & 0.0000 & 0.0000 & 0.0000 \\
\hline & \multicolumn{4}{|c|}{$\begin{array}{l}\text { The number of SCIE literature published by the CAS } \\
\qquad(\mathrm{t}+3)\end{array}$} & \multicolumn{4}{|c|}{$\begin{array}{l}\text { The number of SCIE literature published by the CAS } \\
\text { (average) }\end{array}$} \\
\hline 1.R value $(\mathrm{CI})$ & $-0.3089^{* *}$ & & & $-0.3195^{*}$ & $-0.3923^{*}$ & & & $-0.3470^{*}$ \\
\hline 2. $\mathrm{R}$ value $(\mathrm{CU})$ & & $-0.0230^{* * * *}$ & & $-0.0210^{* * * *}$ & & $-0.0225^{* * * *}$ & & $-0.0199^{* * *}$ \\
\hline 3.R value (CIU) & & & $-0.0361^{* * *}$ & $-0.0305^{* *}$ & & & $-0.0232^{* *}$ & $-0.0218^{* *}$ \\
\hline 4.Pre-sample SCIE literature $[\ln ]^{\mathrm{a}}$ & $0.1828^{* * * *}$ & $0.1315^{*}$ & $0.2038^{* * *}$ & $0.1229^{* * * *}$ & $0.2557^{* * *}$ & $0.3649^{* * *}$ & $0.3895^{* *}$ & $0.2119^{* *}$ \\
\hline 5.Professional researchers $[\ln ]^{\mathrm{a}}$ & $0.0539^{*}$ & $0.0688^{*}$ & $0.0781^{*}$ & $0.0726^{*}$ & $0.0695^{*}$ & $0.0765^{*}$ & $0.0701^{*}$ & $0.0750^{* *}$ \\
\hline 6.Research funds $[\ln ]^{\mathrm{a}}$ & $0.4721^{* * * *}$ & $0.4210^{* * *}$ & $0.4595^{* * *}$ & $0.4380^{* * * *}$ & $0.3278^{* * * *}$ & $0.3010^{* * * *}$ & $0.3576^{* * *}$ & $0.3340^{* * * *}$ \\
\hline Constant & $1.3103^{* * *}$ & $1.2093^{* * *}$ & $1.2280^{* * * *}$ & $1.0530^{* * * *}$ & $0.7298^{* *}$ & $0.6045^{* *}$ & $0.9202^{* *}$ & $1.1028^{* *}$ \\
\hline Wald chi2 & 2836.45 & 2938.16 & 3216.20 & 4352.50 & 4280.13 & 4306.8. & 45360.52 & 5122.70 \\
\hline Log likelihood & -103.105 & -102.1232 & -101.0410 & -99.2012 & -98.0233 & -99.1862 & -97.4738 & -96.3240 \\
\hline Probe $>$ chi 2 & 0.0000 & 0.0000 & 0.0000 & 0.0000 & 0.0000 & 0.0000 & 0.0000 & 0.0000 \\
\hline
\end{tabular}

$* \mathrm{P}<0.1 \quad * * \mathrm{P}<0.05 \quad * * * \mathrm{P}<0.01 ;{ }^{\text {a }}$ The natural logarithm of a variable is denoted by suffix [ln] 
Table 3. The negative binomial regression models for the moderating effect of $R$ value

\begin{tabular}{|c|c|c|c|c|c|c|c|c|}
\hline & \multicolumn{4}{|c|}{$\begin{array}{l}\text { The number of SCIE literature published by the CAS } \\
\qquad(\mathrm{t}+1)\end{array}$} & \multicolumn{4}{|c|}{$\begin{array}{l}\text { The number of SCIE literature published by the CAS } \\
\qquad(\mathrm{t}+2)\end{array}$} \\
\hline & Model 17 & Model 18 & Model 19 & Model 20 & Model 21 & Model 22 & Model 23 & Model 24 \\
\hline 1.Pre-sample SCIE literature $[\ln ]^{\mathrm{a}}$ & $0.6632^{* * * *}$ & $0.7151^{* * * *}$ & $0.6890^{* * *}$ & $0.6016^{* * * *}$ & $0.6127^{* * *}$ & $0.5765^{* * *}$ & $0.6507^{* * *}$ & $0.5328^{* * *}$ \\
\hline 2.Professional researchers $[\ln ]^{\mathrm{a}}$ & $0.5560^{* * * *}$ & $0.5021^{* *}$ & $0.4227^{* *}$ & $0.3317^{*}$ & $0.2138^{* *}$ & $0.1975^{* *}$ & $0.1872^{* *}$ & $0.1799^{* *}$ \\
\hline 3.Research funds $[\ln ]^{\mathrm{a}}$ & $0.8022^{* * *}$ & $0.9210^{* * * *}$ & $1.0522^{* * * *}$ & $0.7737^{* * * *}$ & $0.7158^{* * * *}$ & $0.7821^{* * *}$ & $0.7480^{* * * *}$ & $0.6930^{* * *}$ \\
\hline 4.R value $(\mathrm{CI})$ & $-0.5538^{*}$ & $-0.6722^{*}$ & $-0.5498^{*}$ & $-0.5068^{*}$ & $-0.6826^{*}$ & $-0.6853^{*}$ & $-0.7822^{*}$ & $-0.6085^{*}$ \\
\hline 5.R value $(\mathrm{CU})$ & $-0.0046^{* *}$ & $-0.0051^{* * *}$ & $-0.0044^{* *}$ & $-0.0023^{* *}$ & $-0.0160^{* * *}$ & $-0.0165^{* * *}$ & $-0.0173^{* * *}$ & $-0.0152^{* *}$ \\
\hline 6.R value (CIU) & $-0.0168^{* *}$ & $-0.0199^{* *}$ & $-0.0227^{* *}$ & $-0.0132^{* *}$ & $-0.0202^{* *}$ & $-0.0170^{* *}$ & $-0.0190^{* *}$ & $-0.0153^{* *}$ \\
\hline 7.R value $(\mathrm{CI}) \times$ Professional researchers $[\ln ]^{\mathrm{a}}$ & $-0.4720^{*}$ & & & $-0.4451^{*}$ & $-0.4879^{*}$ & & & $-0.4642^{*}$ \\
\hline $8 . \mathrm{R}$ value $(\mathrm{CI}) \times$ Research funds $[\mathrm{ln}]^{\mathrm{a}}$ & $-0.1015^{*}$ & & & $-0.0960^{*}$ & $-0.1121^{*}$ & & & $-0.0962^{*}$ \\
\hline 9.R value $(\mathrm{CU}) \times$ Professional researchers $[\ln ]^{\mathrm{a}}$ & & $-0.2402^{* *}$ & & $-0.2032^{* *}$ & & $-0.1409^{* *}$ & & $-0.1230^{* *}$ \\
\hline 10.R value $(\mathrm{CU}) \times$ Research funds $[\ln ]^{\mathrm{a}}$ & & $-0.1622^{* * *}$ & & $-0.1423^{* *}$ & & $-0.1268^{* * *}$ & & $-0.1047^{* *}$ \\
\hline 11. $\mathrm{R}$ value $(\mathrm{CIU}) \times$ Professional researchers $[\ln ]^{\mathrm{a}}$ & & & $-0.2962^{* *}$ & $-0.2636^{* *}$ & & & $-0.1665^{* *}$ & $-0.1422^{* *}$ \\
\hline 12.R value $(\mathrm{CIU}) \times$ Research funds $[\mathrm{ln}]^{\mathrm{a}}$ & & & $-0.0519^{* *}$ & $-0.0494^{* *}$ & & & $-0.0401^{* *}$ & $-0.0345^{* *}$ \\
\hline Constant & $1.6250^{* * *}$ & $1.3907^{* * *}$ & $1.5401^{* * *}$ & $1.8228^{* *}$ & $0.5637^{* * *}$ & $0.4665^{* *}$ & $0.5227^{* *}$ & $0.6818^{* * *}$ \\
\hline Wald chi2 & 2646.14 & 3290.20 & 2463.82 & 4085.70 & 3882.50 & 2907.65 & 2802.42 & 4539.16 \\
\hline Log likelihood & -112.0550 & -111.7858 & -113.0735 & -101.3247 & -106.2541 & -108.2033 & -107.3748 & -86.6816 \\
\hline Probe $>$ chi 2 & 0.0000 & 0.0000 & 0.0000 & 0.0000 & 0.0000 & 0.0000 & 0.0000 & 0.0000 \\
\hline
\end{tabular}

${ }^{*} \mathrm{P}<0.1 \quad{ }^{* *} \mathrm{P}<0.05 \quad{ }^{* * *} \mathrm{P}<0.01 ;{ }^{\text {a }}$ The natural logarithm of a variable is denoted by suffix [ln]. 
Table 3 (Continued)

\begin{tabular}{|c|c|c|c|c|c|c|c|c|}
\hline & \multicolumn{4}{|c|}{$\begin{array}{l}\text { The number of SCIE literature published by the CAS } \\
\qquad(\mathrm{t}+3)\end{array}$} & \multicolumn{4}{|c|}{$\begin{array}{l}\text { The number of SCIE literature published by the CAS } \\
\text { (average) }\end{array}$} \\
\hline & Model 25 & Model 26 & Model 27 & Model 28 & Model 29 & Model 30 & Model 31 & Model 32 \\
\hline 1.Pre-sample SCIE literature $[\mathrm{ln}]^{\mathrm{a}}$ & $0.3266^{* * *}$ & $0.4075^{* * *}$ & $0.3940^{* * *}$ & $0.2841^{* * *}$ & $0.4880^{* * *}$ & $0.4938^{* * *}$ & $0.4723^{* * *}$ & $0.3601^{* * *}$ \\
\hline 2.Professional researchers $[\ln ]^{\mathrm{a}}$ & $0.3450^{* *}$ & $0.5458^{* *}$ & $0.3627^{* *}$ & $0.4520^{\text {** }}$ & $0.3014^{* *}$ & $0.3326^{* *}$ & $0.3060^{* *}$ & $0.2932^{* *}$ \\
\hline 3.Research funds $[\ln ]^{\mathrm{a}}$ & $0.2944^{* * *}$ & $0.2669^{* * * *}$ & $0.2472^{* * *}$ & $0.2119^{* * * *}$ & $0.6677^{* * * *}$ & $0.6834^{* *}$ & $0.6940^{* * * *}$ & $0.5570^{* * * *}$ \\
\hline 4. $\mathrm{R}$ value $(\mathrm{CI})$ & $-0.2858^{*}$ & $-0.3941^{*}$ & $-0.2925^{*}$ & $-0.2509^{*}$ & $-0.3832^{*}$ & $-0.4822^{*}$ & $-0.4929^{*}$ & $-0.3202^{*}$ \\
\hline 5.R value $(\mathrm{CU})$ & $-0.0245^{* * *}$ & $-0.0328^{* * * *}$ & $-0.0278^{* * *}$ & $-0.0236^{* *}$ & $-0.0195^{* * *}$ & $-0.0189^{* * *}$ & $-0.0190^{* * *}$ & $-0.0174^{* *}$ \\
\hline 6.R value (CIU) & $-0.0242^{* *}$ & $-0.0198^{* *}$ & $-0.0181^{* *}$ & $-0.0191^{* *}$ & $-0.0119^{* *}$ & $-0.0152^{* *}$ & $-0.0120^{* *}$ & $-0.0103^{* * * *}$ \\
\hline 7.R value $(\mathrm{CI}) \times$ Professional researchers $[\mathrm{ln}]^{\mathrm{a}}$ & $-0.4515^{*}$ & & & $-0.4019^{*}$ & $-0.5313^{*}$ & & & $-0.5007^{*}$ \\
\hline 8.R value $(\mathrm{CI}) \times$ Research funds $[\ln ]^{\mathrm{a}}$ & $-0.0732^{*}$ & & & $-0.0652^{*}$ & $-0.1060^{*}$ & & & $-0.0883^{*}$ \\
\hline 9. $\mathrm{R}$ value $(\mathrm{CU}) \times$ Professional researchers $[\ln ]^{\mathrm{a}}$ & & $-0.0795^{* *}$ & & $-0.0708^{* * *}$ & & $-0.1705^{* *}$ & & $-0.1520^{* *}$ \\
\hline 10.R value $(C U) \times$ Research funds $[\ln ]^{\mathrm{a}}$ & & $-0.1103^{* * * *}$ & & $-0.1025^{* * *}$ & & $-0.1628^{* * *}$ & & $-0.1428^{* * * *}$ \\
\hline 11. $\mathrm{R}$ value $(\mathrm{CIU}) \times$ Professional researchers $[\mathrm{ln}]^{\mathrm{a}}$ & & & $-0.1162^{* *}$ & $-0.1100^{* *}$ & & & $-0.1347^{* *}$ & $-0.1285^{* *}$ \\
\hline 12. $\mathrm{R}$ value $(\mathrm{CIU}) \times$ Research funds $[\ln ]^{\mathrm{a}}$ & & & $-0.0812^{* *}$ & $-0.0687^{* *}$ & & & $-0.0694^{* *}$ & $-0.0595^{* *}$ \\
\hline Constant & $0.5320^{* * *}$ & $0.4625^{* * *}$ & $0.4998^{* *}$ & $0.6625^{\text {*** }}$ & $0.9652^{* *}$ & $1.2055^{* * *}$ & $0.9538^{* * *}$ & $1.1550^{* * *}$ \\
\hline Wald chi2 & 5960.12 & 5118.53 & 5088.46 & 7229.35 & 3951.36 & 4086.58 & 4002.98 & 5861.58 \\
\hline Log likelihood & -115.7334 & -112.7143 & -117.3583 & -100.2542 & -106.4560 & -111.6270 & -109.9150 & -93.5052 \\
\hline Probe > chi2 & 0.0000 & 0.0000 & 0.0000 & 0.0000 & 0.0000 & 0.0000 & 0.0000 & 0.0000 \\
\hline
\end{tabular}


To better reveal the interaction effects of the TH interactions and the research investments on the scientific performance of CAS, six interaction terms produced by three $R$ values (i.e., $R$ value (CI), $R$ value (CU) and $R$ value (CIU)), respectively multiplying two variables of research investments (i.e., professional researchers and research funds) are added step by step based on Models 4, 8, 12 and 16. Moreover, the models are evaluated by respectively fixing one-year, two-year, three-year lag and the average value over three lagging years for the robustness of research findings. The estimated results of 16 Models in Table 3 clearly show that the regression results for the interaction effects of $R$ values and research investments are consistent and stable across all models, suggesting that the regression results are robust. More specifically, as shown in Models 17, 21, 25 and 29, the coefficients for both $R$ value $(\mathrm{CI}) \times$ professional researchers and $R$ value $(\mathrm{CI}) \times$ research funds are negative and statistically significant. This proves that the bilateral interactions between the CAS and industries are conducive to enhancing the effect of research investments on the scientific performance of the CAS. Similarly, the results in Models 18, 22, 26 and 30 show that the coefficients for both $R$ value $(\mathrm{CU}) \times$ professional researchers and $R$ value $(\mathrm{CU}) \times$ research funds are also negative and statistically significant. This suggests that the bilateral interactions between the CAS and universities can positively moderate the relationships between research investments and the scientific performance of the CAS. By comparing interaction terms between $R$ value $(\mathrm{CU}) \times$ research investments and $R$ value $(\mathrm{CI}) \times$ research investments in term of the significance of their coefficients, it is clear that the moderating effects of bilateral interactions between CAS and universities exhibit more significance than that of bilateral interactions between CAS and industries. In addition, it is clear that the coefficients for both $R$ value $(\mathrm{CIU}) \times$ professional researchers and $R$ value $(\mathrm{CIU}) \times$ research funds are negative and statistically significant in Models 19, 23, 27 and 31, indicating that the TH synergy among the CAS, industries and universities is conducive to enhancing the effect of research investments on the scientific performance of the CAS. The regression results of Models 20, 24, 28 and 32 show that the simultaneous effects of six interaction terms $-R$ value $(\mathrm{CI}) \times$ professional researchers; $R$ value $(\mathrm{CI}) \times$ research funds; $R$ value $(\mathrm{CU}) \times$ professional researchers; $R$ value $(\mathrm{CU}) \times$ research funds; $R$ value $(\mathrm{CIU}) \times$ professional researchers; and $R$ value $(\mathrm{CIU}) \times$ research funds - are negative and statistically significant. Overall, the estimated results in Table 3 confirm that the bilateral/trilateral interactions among innovation organizations can positively moderate the relationship between research investments and scientific performance. Thus, Hypothesis 2 receives support.

To vividly reveal the moderating effect of bilateral and trilateral interactions between/among CAS, industries and universities on the relationship between research investments and scientific performance, the $R$ values are divided into high and low groups according to their median. The 
interaction effects between each type of $R$ values (i.e., $R$ value (CI), $R$ value (CU) and $R$ value (CIU)) and research investments (i.e., professional researchers and research funds) are drawn. Specifically, the interaction effects of $R$ values and professional researchers are displayed in Figure 3, and those of $R$ values and research funds are demonstrated in Figure 4 .
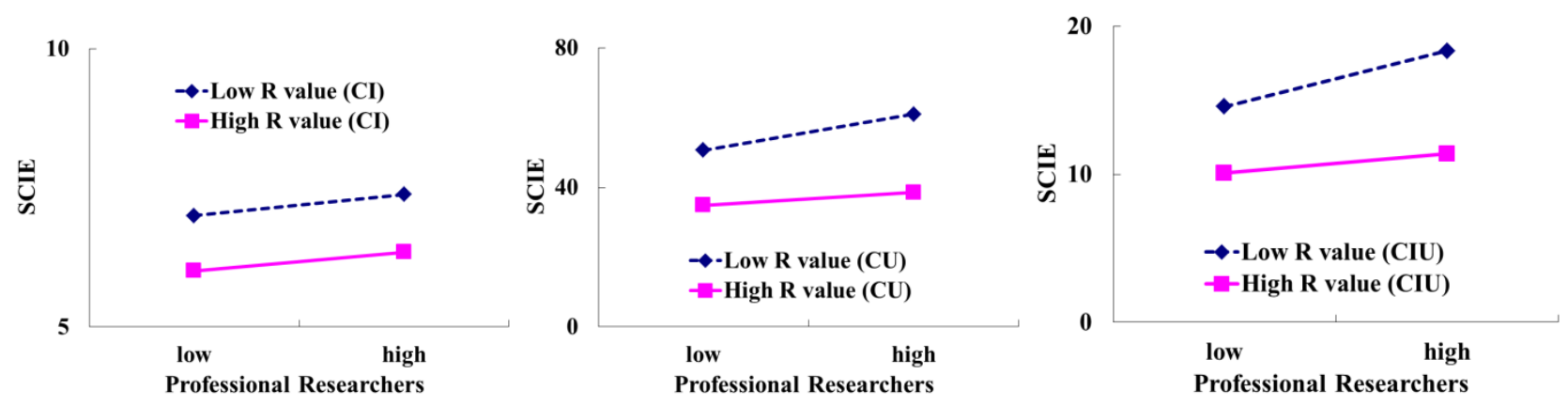

Figure 3: The interactions of $R$ value and professional researchers
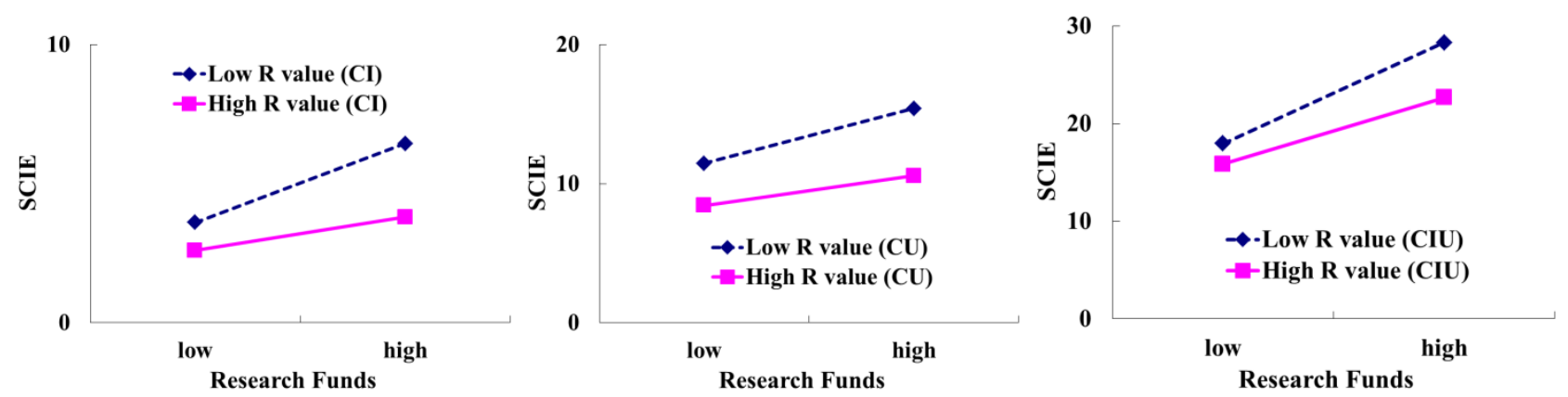

Figure 4: The interactions of $R$ value and research funds

As illustrated in Figures 3 and 4, the main impacts of research investments including professional researchers and research funds on the CAS's scientific performance are positive. This is in line with the knowledge-production function introduced by Griliches (1979). Furthermore, Figures 3 and 4 vividly demonstrate the interactions between $R$ value and research investments. As shown, when $R$ value is lower, or, in other words, becomes more negative, the positive effect of research investments on the CAS's scientific outputs is enhanced, indicating that the moderating effects of three types of $R$ values ( $R(\mathrm{CI}), R(\mathrm{CU})$ and $R(\mathrm{CIU}))$ on the relationship between each type of research investments (professional researchers and research funds) and scientific performance of the CAS are negative. In other words, the bilateral and trilateral interactions between/among CAS, industries and universities positively moderate the relationship between the research investments and the scientific performance of participants. This is consistent with the results showed in Table 3 , and thus Hypothesis 2 receives strong support. 


\section{Discussions}

This study not only characterizes the dynamic patterns of TH interactions among IUR, but also further reveals how the TH interactions influence the participants' performance. In this manner, this study presents some valuable implications for theory, policy and practice, which are as follows:

\subsection{Implications for theory}

The theoretical implications of this research are twofold. Firstly, compared to extant literature that has neglected the impacts of TH interactions from the academic institutes' perspective, this study contributes to the literature by examining how the $\mathrm{TH}$ interactions among heterogeneous organizations influence the scientific performance of academic institutes. This endeavor is conducive to extending the existing analytical framework of TH theory and offers some enlightenment for future research on the effects of $\mathrm{TH}$ relationships. The $\mathrm{TH}$ theory introduced by Etzkowitz and Leydesdorff (1995) is an influential innovation theory that appeared in the late 20th century, which has been widely adopted since then, particularly in the studies of the knowledge-based economy and innovation. It should be noted that the extant studies are largely confined to the measurement of TH interactions among different actors, and they suffer from a limitation of failing to provide valuable information about the impacts of the TH interactions on the participants' scientific performance. This paper aims to fill this research gap by investigating this topic in the context of the TH system of IUR relations.

Secondly, this study enriches the empirical research on TH theory in non-Western contexts. This contributes to developing a general and flexible $\mathrm{TH}$ innovation theory for investigating the non-linear interactions or synergy among the innovation organizations in different national contexts. It is well known that TH theory is rooted in developed (Western) countries (Yoon and Park, 2017), which are characterized by mature institutes, well-established innovation systems, powerful enterprises, world-class universities, and strong indigenous R\&D capabilities (Kafouros et al., 2015). These developed countries differ fundamentally from newly emerging countries such as China in their institutional environments and the S\&T innovation systems. Thus some scholars argued that the TH relationship demonstrated different manners between developed and developing countries, and even held a skeptical view on the validity and application of TH theory in different national contexts beyond the scope of developed countries (Yoon, 2015), suggesting the TH theory needs to be examined and extended in the context of newly industrialized countries, especially in China where the characteristics of the national innovation system are unique. However, little effort so far is devoted to empirically analyzing the patterns of $\mathrm{TH}$ interactions among innovation actors within the 
national innovation system in China. To fill this gap, this study selected the bilateral/trilateral interactions of CAS with enterprises or/and universities as a prototypical example to enrich the $\mathrm{TH}$ empirical studies in China's context. In this manner, this study offers some aspirations for future work depicting TH systems in different contexts of countries, especially the newly emerging countries.

\subsection{Implications for policy}

The findings of this study will be of interest to policy makers who strives to enhance national innovative capability through IUR synergy. This study focuses on IUR interactive relations in the TH framework of UIG systems by considering the S\&T policies issued by government. The results show that the dynamic TH interactions among the research institutes, industries and universities are consist with the guiding role of S\&T policies promulgated by the Chinese government or departments. This indicates the government plays a critical role for enhancing IUR synergy in the innovation system. Moreover, this study finds that the TH synergy among innovation organizations is crucial for improving the participants' scientific performance through promoting the transformation efficiency of research investments. This indicates that enhancing TH synergy is the premise of achieving the ultimate goal of S\&T advancement and increased innovative capability. So, policy makers should introduce a series of initiatives, such as financial supports, tax incentives and other S\&T policies, to create effective institutional arrangements and constitute favorable interactive platforms to promote TH interactions between/among the research institutes, industries and/or universities in the national innovation system.

\subsection{Implications for practice}

Apart from theoretical and political implications, this study also has some practical implications. The research findings show that bilateral and trilateral interactions among research institutes, industries and/or universities can result in high research performance. This suggests that the $\mathrm{TH}$ interactions between/among the different actors are considered as a fertile ground for the actors to gain access to novel knowledge and expertise, learn new skills or techniques, mobilize complementary and unique resources, develop and test academic research, commercialize research findings and acquire funds to support academic research activities. In other words, the $\mathrm{TH}$ interactions can be deemed as a source of innovations (Leydesdorff et al., 2017). So, for the academic institutes, in order to enhance their scientific competitiveness in basic research to meet the 
needs of supporting nationwide S\&T development, they should interact more with industries and universities in order to produce more knowledge.

Moreover, this study shows that the bilateral interactions between the research institutes and domestic enterprises were less dynamic during the entire period 1984-2016, which may be partly due to the low level of absorptive capabilities of China's enterprises, especially the small and medium-sized ones (Zhang et al., 2016). This status quo is likely to hamper the knowledge transfer from academic institutes to industries and thus the goal of maintaining economic growth and social value cannot be achieved. So, the domestic enterprises should increase R\&D investments and set up in-house research centers to boost their research strength and absorptive capacities.

\section{Conclusions and Limitations}

This study examined TH interactions among IUR in China and the impact of TH interactions on the participants' performance is further revealed. These endeavors fill the current research gap since few studies have been devoted to this promising research agenda.

\subsection{Research findings}

Using the indicator of mutual redundancy, this study analyzed the bilateral and trilateral interactions among the TH sectors composed of the CAS, industries and universities. The research result provided robust evidence that the bilateral relationships between the CAS and universities are the dominant form of interactions within the $\mathrm{TH}$ innovation system. In contrast, the research interactions between the CAS and industries are inactive even though the government has released a series of S\&T policies to promote mutual interactions between them. The profound difference between CAS-University interactions and CAS-Industry interactions is partly attributed to the difference in the motives, objectives and preferences and cultures between the enterprises and academic sectors. The former take "private science" as the principles and emphasize that the knowledge is kept in-house, and they pursue commercial exploitation of knowledge, while the latter take "public science" as the principles and search for the strategy of driving research findings to spread freely, rapidly and impartially (Efi, 2014). The different institutional logics prevailing in academia and industry pose a weak relation between them (Bruneel et al., 2010; Kafouros et al., 2015). Besides, as mentioned earlier, the poor absorptive capability of domestic enterprises in China is another reason for the weak relationship between academic institutes and industries in the scientific research field. Previous studies have found that the absorptive capability allows the enterprises to effectively combine internal and external knowledge (Arza, 2010; Barge-Gil, 2010). 
Thus the enterprises with higher levels of absorptive capability are apt to build research links with academic institutes. It is not surprising to find that the industry sector in developed countries participates more frequently in scientific interactions with academic institutes because of its strong absorptive capabilities (Choi et al., 2015). Conversely, many of China's enterprises, especially the small and medium-sized ones, have difficulties in building the research collaboration with academic institutes because of their poor R\&D and absorptive capabilities (Motohashi and Yun, 2007; Perks et al., 2009). So, the large distance of R\&D capabilities between domestic firms and academic institutes may weaken their mutual interactions, suggesting it is important for China to enhance the absorptive capacities of domestic enterprises to facilitate bilateral interactions between academic and industry sectors. In addition, this study finds that the CAS-Industry-University interactions have become increasingly cohesive over the period 1984-2016. This may be attributed to the S\&T policies issued by the Chinese government. To strengthen the knowledge base of innovation, the Chinese government has continuously enhanced the TH synergy among industries, universities and research institutes, and a series of laws and regulations have been issued with the goal of encouraging them to interact creatively with one another. In this circumstance, the IUR synergy has been enhanced.

Moreover, the regression results show that the bilateral and trilateral interactions between/among research institutes, industries or/and universities exert a positive and significant effect on the research institutes' scientific performance. This is in line with the expectation as TH interactions among different organizations enable information, knowledge and other innovative resource to transfer freely across organizational borders. Thus, more research options and tactics are made available and generated endogenously, which is the foundation of knowledge creation and performance improvement. In addition, the closer the research institutes interact with industries and universities, the better chance the research institutes have to acquire heterogeneous knowledge and mobilize the complementary and unique resources from their partners (Galan-Muros and Plewa, 2016). Thus, the TH interactions among innovation organizations can expand knowledge resources, and thereby enhance the innovation organizations' $R \& D$ capabilities and scientific performance. Besides, this study finds that the bilateral and trilateral interactions between/among research institutes, industries or/and universities can positively moderate the relationship between research investments and scientific performance. Why? Previous studies have identified a set of benefits of research interactions between the innovative entities from the academic institutes' perspective, including supplementing additional funding for academic research (Meyer-Krahmer and Schmoch, 1998), testing applications of a theory (Lee, 2000) or acquiring a new perspective from other partners (Hanel and St-Pierre, 2006), which result in better scientific performance given the same level of research investments. This indicates that the research interactions enhance the positive effect of the 
research investments on the academic institutes' scientific performance by improving the efficiency of R\&D input-output processes if everything else is equal. In other words, the TH interactions among innovative entities positively moderate the relationship between research investments and scientific performance.

\subsection{Limitations and future research}

Although this study has uncovered some important research findings, it also suffers from some limitations that may indicate some directions for future research. Firstly, this study, as a novel case, takes the bilateral and trilateral interaction systems of CAS with industries or/and universities as the research sample to examine the effects of TH interactions on the participants' performance. To enhance the robustness of evidence, future studies should broaden the research sample by considering other typical innovation organizations' TH interaction systems. Secondly, the analysis in this study is exclusively based on SCIE publications co-authored by CAS with industries or/and universities. This approach has been adopted in a growing body of published literature (e.g., Fleming et al., 2007; Guan et al., 2015; Schilling and Phelps, 2007), as the co-authored literature can reflect collaborative research and form one important indicator of research links between innovation entities (Katz and Martin, 1997). In fact, the inter-organizational interactions cannot fully be described by only using co-authored SCIE literature, because it is just one type of research outcomes for bilateral/trilateral interactions between/among research institutes with industries or/and universities, and their interactions also generate patents, trade secrets, copyrights and other outputs. Meanwhile, apart from the formal outcomes such as co-authored literature, the TH interactions among research institutes, industries and universities are mostly informal, not necessary for tangible outcomes with codified knowledge. Thus these TH relationships among them cannot be detected by co-authored SCIE literature. So, future studies should collect more indicators and data by survey or statistics to explore the TH interactions. Thirdly, it should be recognized that the IUR interactions also usually occur in the field of technology development, so it might be fruitful to use the co-invented patent literature to explore the characteristics of $\mathrm{TH}$ interactions among research institutes, industries and universities in future studies. Fourthly, even though this study may contribute to extant literature by investigating the TH system of IUR relations in the context of China, it does not further investigate how IUR interact with other helices in the context of the Quadruple (or More) Helix system. Future studies should pay much attention to the quadrilateral or more-lateral interactions in China and other Asian countries, which contribute to developing Quadruple (or More) Helix theory in the non-Western context. Fifthly, the data source of this study relies on the SCIE literature extracted 
from a big database Web of Science. This database has been widely adopted by previous studies over the last several decades. It should be noted that more recent studies, such as Park and Park (2018), have adopted a new approach, namely altmetrics, to implement academic assessment. As Park and Park (2018) noted, altmetrics is a promising way to supplement traditional scholarly assessment methods. Future research should incorporate this new approach into the TH study. Last but not least, following previous TH studies (e.g., Belkhodja and Landry, 2007; Danell and Persson, 2003; Kwon et al., 2012; Leydesdorff and Meyer, 2010; Leydesdorff and Sun, 2009; Park et al., 2005; Park and Leydesdorff, 2010), this study chooses the research institutes as the proxy for government when investigating the IUR interactions within the TH framework. Even though the research institutes to some degree act as an agent assuming the governmental participating role in IUR interactions, it should be noted that the research institutes cannot be equal to government because the former is only a subsidiary body (academic institutes) included in the latter. Besides, it should be noted that the guiding and oversight functions of government sectors by policy tools are simply described when the dynamic patterns of TH interactions among CAS, industries and universities is investigated. How do the S\&T policies have effects on the IUR interactive relations? This interesting topic has not yet been analyzed in this study and should be addressed in future work. 


\section{References}

Abramson, N., 1963. Information Theory and Coding. McGraw-Hill, New York.

Afonso, O., Monteiro, S., Thompson, M., 2012. A growth model for the quadruple helix. Journal of Business Economics \& Management, 13(5), 849-865.

Alexander, A.T., Neyer, A.K., Huizingh, K.R.E., 2016. Introduction to the special issue: transferring knowledge for innovation. R \& D Management 46(2), 51-68.

Anand, J., Oriani, R., Vassolo, R.S., 2010. Alliance activity as a dynamic capability in the face of a discontinuous technological change. Organization Science 21(6), 1213-1232.

Anatan, L., 2018. An institutional perspective of knowledge transfer within university and industry alliance. International Journal of Economic Policy in Emerging Economies, 11(4), 378-395.

Arza, V., 2010. Channels, benefits and risks of public-private interactions for knowledge transfer: conceptual framework inspired by Latin America. Science and Public Policy 37(7), 473-484.

Azagra-Caro, J.M., Barberá-Tomás, D., Edwards-Schachter, M., Tur, E.M., 2017. Dynamic interactions between university-industry knowledge transfer channels: A case study of the most highly cited academic patent. Research Policy, 46(2), 463-474.

Baba, Y., Shichijo, N., Sedita, S.R., 2009. How do collaborations with universities affect firms' innovative performance? The role of "Pasteur scientists" in the advanced materials field. Research Policy 38(5), 756-764.

Bai, C., 2016. The Pioneer Initiative: A New Era in Chinese Research. Small, 12(16), 2115-2117.

Banal-Estanol, A., Jofre-Bonet, M., Lawson, C., 2015. The double-edged sword of industry collaboration: Evidence from engineering academics in the UK. Research Policy 44(6), 1160-1175.

Barge-Gil, A., 2010. Cooperation-based innovators and peripheral cooperators: An empirical analysis of their characteristics and behavior. Technovation 30(3), 195-206.

Belkhodja, O., Landry, R., 2007. The Triple-Helix collaboration: Why do researchers collaborate with industry and the government? What are the factors that influence the perceived barriers? Scientometrics, 70(2), 301-332.

Belsley, D.A., 2005. Regression Diagnostics: Identifying Influential Data and Sources of Collinearity. John Wiley \& Sons, Hoboken, NJ. USA.

Berchicci, L., 2013. Towards an open R\&D system: Internal R\&D investment, external knowledge acquisition and innovative performance. Research Policy 42(1), 117-127.

Biscaro, C., Comacchio, A., 2018. Knowledge creation across worldviews: How metaphors impact and orient group creativity. Organization Science, 29(1), 58-79.

Blais, M.A., 2003. Applied multiple regression/correlation analysis for the behavioral sciences (3rd ed.). Journal of Personality Assessment, 81(3), 293-293.

Blundell, R., Griffith, R., Reenen, J.V., 1995. Dynamic count data models of techno-logical innovation. The Economic Journal 105(429), 333-444.

Bozeman, B., 1987. All organizations are public: Bridging public and private organizational theories. Jossey-Bass Inc Pub.

Bruneel, J., D'Este, P., Salter, A., 2010. Investigating the factors that diminish the barriers to university-industry collaboration. Research Policy 39(7), 858-868.

Cai, Y., 2014. Implementing the Triple Helix model in a non-western context: an institutional logics perspective. Triple Helix 1(1), 1-20.

Callaert, J., Landoni, P., Van Looy, B., Verganti, R., 2015. Scientific yield from collaboration with industry: The relevance of researchers' strategic approaches. Research Policy 44(4), 990-998.

Cameron, A.C., Trivedi, P.K., 2013. Regression Analysis of Count Data. Cambridge University Press, Cambridge, UK.

Carayannis, E.G., Campbell, D.F.J., 2009. "Mode 3" and "Quadruple Helix": Toward a 21st century fractal innovation ecosystem. International Journal of Technology Management, 46(3/4), 201-234.

Carayannis, E.G., Campbell, D.F.J., 2010. Triple Helix, Quadruple Helix and Quintuple Helix and How Do Knowledge, Innovation and the Environment Relate To Each Other? : A Proposed Framework for a Transdisciplinary Analysis of Sustainable Development and Social Ecology. International Journal of Social Ecology \& Sustainable Development, 1, 41-69.

Carayannis, E.G., Grigoroudis, E., Campbell, D.F., Meissner, D., Stamati, D., 2018. The ecosystem as helix: an exploratory theory-building study of regional co-opetitive entrepreneurial ecosystems as Quadruple/Quintuple Helix Innovation Models. R\&d Management, 48(1), 148-162.

Champenois, C., Etzkowitz, H., 2017. From boundary line to boundary space: the creation of hybrid organizations as a Triple Helix micro-foundation. Technovation. (In press) 
Chen, K., Zhang, Y., Zhu, G., Mu, R., 2017. Do research institutes benefit from their network positions in research collaboration networks with industries or/and universities? Technovation. (In press)

Choi, S., Yang, J.S., Park, H.W., 2015. Quantifying the Triple Helix relationship in scientific research: statistical analyses on the dividing pattern between developed and developing countries. Quality \& Quantity 49(4), 1381-1396.

Cohen, W.M., Nelson, R.R., Walsh, J.P., 2002. Links and impacts: The influence of public research on industrial R\&D. Management Science 48(1), 1-23.

Danell, R., Persson, O., 2003. Regional R\&D activities and interactions in the Swedish Triple Helix. Scientometrics, 58(2), 203-218.

De Fuentes, C., Dutrenit, G., 2012. Best channels of academia-industry interaction for long-term benefit. Research Policy, 41(9), 1666-1682.

Demidenko, E., 2013. Mixed Models: Theory and Applications with R. John Wiley \&Sons, Hoboken, NJ, USA.

Efi, A.E., 2014. Synergy between Academic Research and Industrialization: The Search for Development in Nigeria. Human Resource Management Research 4(3), 69-74.

Elvekrok, I., Veflen, N., Nilsen, E.R., Gausdal, A.H., 2018. Firm innovation benefits from regional triple-helix networks. Regional studies, 52(9), 1214-1224.

Etzkowitz, H., 2003. Research groups as \&lsquo;quasi-firms\&rsquo;: the invention of the entrepreneurial university. Research Policy 32(1), 109-121.

Etzkowitz, H., Dzisah, J., 2008. Rethinking development: circulation in the triple helix. Technology Analysis \& Strategic Management 20(6), 653-666.

Etzkowitz, H., Leydesdorff, L., 1995. The Triple Helix -- University-Industry-Government Relations: A Laboratory for Knowledge Based Economic Development. Glycoconjugate Journal 14(1), 14-19.

Etzkowitz, H., Leydesdorff, L., 2000. The dynamics of innovation: from National Systems and "Mode 2" to a Triple Helix of university-industry-government relations. Research Policy 29(2), 109-123.

Eun, J. H., Lee, K., Wu, G., 2006. Explaining the "University-run enterprises" in China: A theoretical framework for university-industry relationship in developing countries and its application to China. Research Policy, 35(9), 1329-1346.

Fleming, L., King, C., III, Juda, A.I., 2007. Small worlds and regional innovation. Organization Science 18(6), 938-954.

$\mathrm{Fu}, \mathrm{X}$. and Li, J. 2016. 'Collaborating with foreign universities for innovation: evidence from Chinese manufacturing firms', International Journal of Technology Management, 70(2/3),193-217.

Galan-Muros, V., Plewa, C., 2016. What drives and inhibits university-business cooperation in Europe? A comprehensive assessement. R \& D Management 46(2), 369-382.

Gao, X., Guo, X., Guan, J., 2014. An analysis of the patenting activities and collaboration among industry-university-research institutes in the Chinese ICT sector. Scientometrics 98(1), 247-263.

Gomes-Casseres, B., Hagedoorn, J., Jaffe, A.B., 2006. Do alliances promote knowledge flows? Journal of Financial Economics 80(1), 5-33.

Gonzalez-Brambila, C.N., Veloso, F.M., Krackhardt, D., 2013. The impact of network embeddedness on research output. Research Policy 42(9), 1555-1567.

Griliches, Z., 1979. Issues in assessing the contribution of R\&D to productivity growth. Journal of Economics 10 , 92-116.

Guan, J., Zhang, J., Yan, Y., 2015. The impact of multilevel networks on innovation. Research Policy 44(3), 545-559.

Guan, J., Zhao, Q., 2013. The impact of university-industry collaboration networks on innovation in nanobiopharmaceuticals. Technological Forecasting and Social Change 80(7), 1271-1286.

Guerrero, M., Urbano, D., 2017. The impact of Triple Helix agents on entrepreneurial innovations' performance: An inside look at enterprises located in an emerging economy. Technological Forecasting and Social Change, 119, 294-309.

Gustafsson, R., Jarvenpaa, S., 2018. Extending community management to industry-university-government organizations. R\&d Management, 48(1), 121-135.

Hanel, P., St-Pierre, M., 2006. Industry-university collaboration by Canadian manufacturing firms. Journal of Technology Transfer 31(4), 485-499.

Hausman, J.A., 1978. Specification tests in econometrics. Econometrica 46(6), 1251-1271.

Hong, W., Su, Y. S., 2013. The effect of institutional proximity in non-local university-industry collaborations: An analysis based on Chinese patent data. Research Policy 42(2), 454-464.

Huang, J.J., Yuan, Y.J., 2014. The value of entrepreneurship in the industry-university cooperation. Studies in Science of Science 32(6), 902-908. 
Ivanova, I., Leydesdorff, L., 2014a. Redundancy Generation in University-Industry-Government Relations: The Triple Helix Modeled, Measured, and Simulated. Scientometrics 99(3), 927-948.

Ivanova, I.A., Leydesdorff, L., 2014b. Rotational symmetry and the transformation of innovation systems in a Triple Helix of university-industry-government relations. Technological Forecasting \& Social Change 86(340), 143-156.

Ivanova, I.A., Leydesdorff, L., 2014c. A simulation model of the Triple Helix of university-industry-government relations and the decomposition of the redundancy. Scientometrics 99(3), 927-948.

Jin, F., Luo, S., 2009. Researching on the Performance Evaluation Index System of Industry-University-Research Institute Collaboration. Scientific Management Research 27(3), 43-46.

Jones, J., de Zubielqui, G.C., 2017. Doing well by doing good: A study of university-industry interactions, innovationess and firm performance in sustainability-oriented Australian SMEs. Technological Forecasting and Social Change, 123, 262-270.

Kafouros, M., Wang, C., Piperopoulos, P., Zhang, M., 2015. Academic collaborations and firm innovation performance in China: The role of region-specific institutions. Research Policy 44(3), 803-817.

Katila, R., Mang, P.Y., 2003. Exploiting technological opportunities: the timing of collaborations. Research Policy 32(2), 317-332.

Katz, J.S., Martin, B.R., 1997. What is research collaboration? Research Policy 26(1), 1-18.

Khan, G.F., Park, W.H., 2011. Measuring the triple helix on the web: Longitudinal trends in the university-industry-government relationship in Korea. Journal of the American Society for Information Science \& Technology, 62(12), 2443-2455.

Kwon, K. S., Park, H.W., So, M., Leydesdorff, L., 2012. Has globalization strengthened South Korea's national research system? National and international dynamics of the Triple Helix of scientific co-authorship relationships in South Korea. Scientometrics, 90(1), 163-176.

Laudel, G., 2002. What do we measure by co-authorships? Research Evaluation 11(1), 3-15.

Laursen, K., Reichstein, T., Salter, A., 2011. Exploring the Effect of Geographical Proximity and University Quality on University-Industry Collaboration in the United Kingdom. Regional studies 45(4), 507-523.

Lavie, D., Drori, I., 2012. Collaborating for Knowledge Creation and Application: The Case of Nanotechnology Research Programs. Organization Science 23(3), 704-724.

Lee, T., Liu, C.-H., Fei, W., Tsang, L.-Y., 2018. Knowledge Transfer in an Organization: Effects of Individual and Departmental Network Centrality, Academy of Management Proceedings. Academy of Management Briarcliff Manor, NY 10510, p. 13099.

Lee, Y.H., Kim, Y., 2016. Analyzing interaction in R\&D networks using the Triple Helix method: Evidence from industrial R\&D programs in Korean government. Technological Forecasting and Social Change 110, 93-105.

Lee, Y.S., 2000. The sustainability of university-industry research collaboration: An empirical assessment. The Journal of Technology Transfer 25(2), 111-133.

Leydesdorff, L., 2003. The mutual information of university-industry-government relations: An indicator of the Triple Helix dynamics. Scientometrics 58(2), 445-467.

Leydesdorff, L., 2010. The Knowledge-Based Economy and the Triple Helix Model. Annual Review of Information Science and Technology, 44, 367-417.

Leydesdorff, L., 2012. The Triple Helix, Quadruple Helix, ..., and an N-Tuple of Helices: Explanatory Models for Analyzing the Knowledge-Based Economy? Journal of the Knowledge Economy, 3(1), 25-35.

Leydesdorff, L., 2018. Synergy in Knowledge-Based Innovation Systems at National and Regional Levels: The Triple-Helix Model and the Fourth Industrial Revolution. Journal of Open Innovation: Technology, Market, and Complexity, 4(2), 16.

Leydesdorff, L., Etzkowitz, H., Ivanova, I., Meyer, M.S., 2017. The Measurement of Synergy in Innovation Systems: Redundancy Generation in a Triple Helix of University-Industry-Government Relations, in: Gla"nzel, H., Moed, H., Schmoch, U., Thelwall, M. (Eds.), Springer handbook of science and technology indicators. Springer, Heidelberg.

Leydesdorff, L., Ivanova, I.A., 2014. Mutual Redundancies in Interhuman Communication Systems: Steps Toward a Calculus of Processing Meaning. Journal of the Association for Information Science \& Technology 65(2), 386-399.

Leydesdorff, L., Ivanova, I.A., 2016. 'Open Innovation 'and 'Triple Helix' Models of Innovation: Can Synergy in Innovation Systems Be Measured? Journal of Open Innovation: Technology, Market, and Complexity, 2(1), 11.

Leydesdorff, L., Meyer, M., 2006. Triple Helix indicators of knowledge-based innovation systems: Introduction to the special issue. Research Policy 35(10), 1441-1449. 
Leydesdorff, L., Meyer, M., 2010. The decline of university patenting and the end of the Bayh-Dole effect. Scientometrics, 83(2), 355-362.

Leydesdorff, L., Park, H.W., 2014. Can synergy in Triple Helix relations be quantified? A review of the development of the Triple Helix indicator. Triple Helix 1(4), 1-19.

Leydesdorff, L., Petersen, A.M., Ivanova, I., 2017. Self-organization of meaning and the reflexive communication of information. Social Science Information, 56(1), 4-27.

Leydesdorff, L., Sun, Y., 2009. National and international dimensions of the Triple Helix in Japan: University-industry-government versus international coauthorship relations. Journal of the American Society for Information Science and Technology 60(4), 778-788.

Leydesdorff, L., Zhou, P., 2014. Measuring the knowledge-based economy of China in terms of synergy among technological, organizational, and geographic attributes of firms. Scientometrics 98(3), 1703-1719.

Li, Y., Arora, S., Youtie, J., Shapira, P., 2016. Using web mining to explore Triple Helix influences on growth in small and mid-size firms. Technovation, doi.org/10.1016/j.technovation.2016.01.002

Liang, L., Chen, L., Wu, Y., Yuan, J., 2012. The role of Chinese universities in enterprise-university research collaboration. Scientometrics 90(1), 253-269.

Liu, F.-c., Simon, D.F., Sun, Y.-t., Cao, C., 2011. China's innovation policies: Evolution, institutional structure, and trajectory. Research Policy 40(7), 917-931.

Liu, X.L., Zhi, T.T., 2010. China is catching up in science and innovation: the experience of the Chinese Academy of Sciences. Science and Public Policy 37(5), 331-342.

Liu, X.L., White, S., 2001. Comparing innovation systems: a framework and application to China's transitional context. Research Policy 30(7), 1091-1114.

McAdam, M., Debackere, K., 2018. Beyond 'triple helix'toward 'quadruple helix'models in regional innovation systems: Implications for theory and practice. R\&D Management, 48(1), 3-6.

Mêgnigbêto, E., 2018a. Correlation between transmission power and some indicators used to measure the knowledge-based economy: case of six OECD countries. Journal of the Knowledge Economy, 9(4), 1168-1183.

Mêgnigbêto, E., 2018b. Modelling the Triple Helix of university-industry-government relationships with game theory: Core, Shapley value and nucleolus as indicators of synergy within an innovation system. Journal of Informetrics, 12(4), 1118-1132.

Meyer-Krahmer, F., Schmoch, U., 1998. Science-based technologies: university-industry interactions in four fields. Research Policy 27(8), 835-851.

Miller, K., McAdam, R., McAdam, M., 2018. A systematic literature review of university technology transfer from a quadruple helix perspective: toward a research agenda. R\&d Management, 48(1), 7-24.

Miller, K., Mcadam, R., Moffett, S., Alexander, A., Puthusserry, P., 2016. Knowledge transfer in university quadruple helix ecosystems: an absorptive capacity perspective. R \& D Management 46(2), 383-399.

Motohashi, K., Yun, X., 2007. China's innovation system reform and growing industry and science linkages. Research Policy 36(8), 1251-1260.

Park, H., Park, H.W., 2018. Research evaluation of Asian countries using altmetrics: comparing South Korea, Japan, Taiwan, Singapore, and China. Scientometrics, 1-18.

Park, H.W., 2014a. An interview with Loet Leydesdorff: the past, present, and future of the triple helix in the age of big data. Scientometrics, 99(1), 199-202.

Park, H.W., 2014b. Transition from the Triple Helix to N-Tuple Helices? An interview with Elias G. Carayannis and David F. J. Campbell. Scientometrics, 99(1), 203-207.

Park, H.W., Hong, H.D., Leydesdorff, L., 2005. A comparison of the knowledge-based innovation systems in the economies of South Korea and the Netherlands using Triple Helix indicators. Scientometrics, 65(1), 3-27.

Park, H.W., Leydesdorff, L., 2010. Longitudinal trends in networks of university-industry-government relations in South Korea: The role of programmatic incentives. Research Policy 39(5), 640-649.

Paruchuri, S., 2010. Intraorganizational networks, interorganizational networks, and the impact of central inventors: A longitudinal study of pharmaceutical firms. Organization Science 21(1), 63-80.

Perkmann, M., King, Z., Pavelin, S., 2011. Engaging excellence? Effects of faculty quality on university engagement with industry. Research Policy 40(4), 539-552.

Perkmann, M., Walsh, K., 2009. The two faces of collaboration: impacts of university-industry relations on public research. Industrial and Corporate Change 18(6), 1033-1065.

Perks, H., Kahn, K., Zhang, C., 2009. An Empirical Evaluation of R\&D-Marketing NPD Integration in Chinese Firms: The Guanxi Effect. Journal of product innovation management 26(6), 640-651.

Phillips, F., 2014. Triple helix and the circle of innovation. J. Contemp. East. Asia, 13(1), 57-68. 
Rau, C., Möslein, K.M., Neyer, A.K., 2016. Playing possum, hide-and-seek, and other behavioral patterns: knowledge boundaries at newly emerging interfaces. R \& D Management 46(2), 341-353.

Rho, W.J., 2014. Triple Helix for Social Innovation: The Saemaul Undong for Eradicating Poverty. Journal of Contemporary Eastern Asia, 13(1), 39-55.

Ryan, P., Geoghegan, W., Hilliard, R., 2018. The microfoundations of firms' explorative innovation capabilities within the triple helix framework. Technovation.

Santoro, G., Bresciani, S., Papa, A., 2018. Collaborative modes with Cultural and Creative Industries and innovation performance: The moderating role of heterogeneous sources of knowledge and absorptive capacity. Technovation.

Schillebeeckx, S.J.D., Chaturvedi, S., George, G., King, Z., 2015. What do I want? The effects of individual aspiration and relational capability on collaboration preferences. Strategic Management Journal 12(3), 363-379.

Schilling, M.A., Phelps, C.C., 2007. Interfirm collaboration networks: The impact of large-scale network structure on firm innovation. Management Science 53(7), 1113-1126.

Shannon, C.E., 1948. A mathematical theory of communication. Bell System Technical Journal 27(3), 379-423.

Shannon, C.E., Weaver, W., 1949. The Mathematical Theory of Communication. University of Illinois Press, Urbana, USA.

Sun, Y., Cao, C., 2015. Intra- and inter-regional research collaboration across organizational boundaries: Evolving patterns in China. Technological Forecasting and Social Change 96, 215-231.

Sun, Y., Negishi, M., 2010. Measuring the relationships among university, industry and other sectors in Japan's national innovation system: a comparison of new approaches with mutual information indicators. Scientometrics 82(3), 677-685.

Tsai, W., 2001. Knowledge transfer in intraorganizational networks: Effects of network position and absorptive capacity on business unit innovation and performance. Academy of Management Journal 44(5), 996-1004.

van Geenhuizen, M., 2016. Living Labs as boundary-spanners between Triple Helix actors. Journal of Contemporary Eastern Asia, 15(1), 78-97.

Wasserman, S., Faust, K., 1994. Social Network Analysis: Methods and applications. Cambridge university Press, Cambridge, UK.

Williams, L.D., Woodson, T.S., 2012. The future of innovation studies in less economically developed countries. Minerva, 50(2), 221-237.

Yang, H., Jung, W.S., 2016. Assessing Knowledge Structures for Public Research Institutes. Journal of Contemporary Eastern Asia, 15(1), 27-40.

Ye, F.Y., Yu, S.S., Leydesdorff, L., 2013. The Triple Helix of University-Industry-Government relations at the country level and its dynamic evolution under the pressures of globalization. Journal of the American Society for Information Science and Technology, 64(11), 2317-2325.

Yoon, J., 2015. The evolution of South Korea's innovation system: moving towards the triple helix model? Scientometrics 104(1), 265-293.

Yoon, J., Park, H.W., 2017. Triple helix dynamics of South Korea's innovation system: a network analysis of inter-regional technological collaborations. Quality \& Quantity 51(3), 989-1007.

Zhang, D., Banker, R.D., Li, X., Liu, W., 2011. Performance impact of research policy at the Chinese Academy of Sciences. Research Policy 40(6), 875-885.

Zhang, Y., Chen, K., Zhu, G., Yam, R.C.M., Guan, J., 2016. Inter-organizational scientific collaborations and policy effects: an ego-network evolutionary perspective of the Chinese Academy of Sciences. Scientometrics 108(3), $1383-1415$.

Zhao, S.L., Cacciolatti, L., Lee, S.H., Song, W., 2015. Regional collaborations and indigenous innovation capabilities in China: A multivariate method for the analysis of regional innovation systems. Technological Forecasting and Social Change 94, 202-220. 